\title{
Air-snow exchange of nitrate: a modelling approach to investigate physicochemical processes in surface snow at Dome $\mathrm{C}$, Antarctica
}

\author{
Josué Bock $^{1, a}$, Joël Savarino ${ }^{2,3}$, and Ghislain Picard ${ }^{2,3}$ \\ ${ }^{1}$ Centre for Ocean and Atmospheric Sciences, School of Environmental Sciences, University of East Anglia, \\ Norwich Research Park, Norfolk, NR4 7TJ, Norwich, UK \\ ${ }^{2}$ Université Grenoble Alpes, Laboratoire de Glaciologie et Géophysique de l'Environnement (LGGE), \\ 38041 Grenoble, France \\ ${ }^{3}$ CNRS, LGGE UMR5183, 38041 Grenoble, France \\ anow at: Météo France, CNRM, Centre National de Recherches Météorologiques, UMR3589, \\ 42 avenue G. Coriolis, 31057 Toulouse CEDEX 1, France
}

Correspondence to: Josué Bock (josue.bock@ meteo.fr)

Received: 11 February 2016 - Published in Atmos. Chem. Phys. Discuss.: 8 March 2016

Revised: 21 September 2016 - Accepted: 22 September 2016 - Published: 7 October 2016

\begin{abstract}
Snowpack is a multiphase (photo)chemical reactor that strongly influences the air composition in polar and snow-covered regions. Snowpack plays a special role in the nitrogen cycle, as it has been shown that nitrate undergoes numerous recycling stages (including photolysis) in the snow before being permanently buried in the ice. However, the current understanding of these physicochemical processes remains very poor. Several modelling studies have attempted to reproduce (photo)chemical reactions inside snow grains, but these have relied on strong assumptions to characterise snow reactive properties, which are not well defined. Airsnow exchange processes such as adsorption, solid-state diffusion, or co-condensation also affect snow chemical composition. Here, we present a physically based model of these processes for nitrate. Using as input a 1-year-long time series of atmospheric nitrate concentration measured at Dome C, Antarctica, our model reproduces with good agreement the nitrate measurements in the surface snow. By investigating the relative importance of the main exchange processes, this study shows that, on the one hand, the combination of bulk diffusion and co-condensation allows a good reproduction of the measurements (correlation coefficient $r=0.95$ ), with a correct amplitude and timing of summer peak concentration of nitrate in snow. During winter, nitrate concentration in surface snow is mainly driven by thermodynamic equilibrium, whilst the peak observed in summer is explained by the kinetic process of co-condensation. On the other hand, the
\end{abstract}

adsorption of nitric acid on the surface of the snow grains, constrained by an already existing parameterisation for the isotherm, fails to fit the observed variations. During winter and spring, the modelled concentration of adsorbed nitrate is respectively 2.5 and 8.3 -fold higher than the measured one. A strong diurnal variation driven by the temperature cycle and a peak occurring in early spring are two other major features that do not match the measurements. This study clearly demonstrates that co-condensation is the most important process to explain nitrate incorporation in snow undergoing temperature gradient metamorphism. The parameterisation developed for this process can now be used as a foundation piece in snowpack models to predict the inter-relationship between snow physical evolution and snow nitrate chemistry.

\section{Introduction}

\subsection{Nitrogen cycle and snow chemistry}

The nitrogen cycle governs atmospheric oxidants budget through the photochemistry of nitrogen oxides $\left(\mathrm{NO}_{x}=\mathrm{NO}+\mathrm{NO}_{2}\right)$, which are strongly coupled with ozone $\left(\mathrm{O}_{3}\right)$ and hydroxyl $(\mathrm{OH})$ chemistry in the troposphere (Seinfeld and Pandis, 1998; Finlayson-Pitts and Pitts, 2000). Atmospheric nitrate is the end product of $\mathrm{NO}_{x}$ oxidation, and the snowpack (and subsequently the firn and ice) acts 
as a sink. Temporal variations in the nitrate concentration recorded in ice cores (Legrand and Mayewski, 1997) could thus provide information about the oxidative capacity of the atmosphere in past times (Dibb et al., 1998), or even about past solar activity (Traversi et al., 2012). However, as illustrated by Davis et al. (2008, their Fig. 2), several post-deposition processes occur in the snow and hamper our current ability to interpret ice core records of nitrate. As first evidence of these post-deposition processes, $\mathrm{NO}_{x}$ has been shown to be produced in sunlit snowpack (Honrath et al., 1999, 2000b, 2002; Jones et al., 2000; Beine et al., 2002). A production pathway involving nitrate photolysis in snow was rapidly elucidated afterwards (Jones et al., 2000; Dibb et al., 2002; Honrath et al., 2002). These pioneering works drove numerous field campaigns (e.g. SNOW99: Honrath et al., 2000b; ISCAT2000: Davis et al., 2004; ANTCI: Eisele et al., 2008; CHABLIS: Jones et al., 2008; OPALE: Preunkert et al., 2012), as well as laboratory studies (Honrath et al., 2000a; Dubowski et al., 2001, 2002; Chu and Anastasio, 2003, 2007; Cotter et al., 2003; Zhu et al., 2010; Meusinger et al., 2014; Berhanu et al., 2014) and modelling studies (Jacobi and Hilker, 2007; Boxe and Saiz-Lopez, 2008; Liao and Tan, 2008; Bock and Jacobi, 2010; Thomas et al., 2011; Toyota et al., 2014; Erbland et al., 2015; Murray et al., 2015), in order to improve the understanding of the underlying processes responsible for the nitrogen recycling inside the snowpack. These studies focused on the nitrate photolysis in the photic zone of the snowpack and the subsequent release of $\mathrm{NO}_{x}$ to the overlying atmosphere.

None of these studies investigated the physicochemical uptake processes of atmospheric nitrate into snow. However, it has been established that several physical processes also affect snow chemical composition (Dominé et al., 2008). Numerous experimental studies of adsorption on ice surfaces have demonstrated that several chemical compounds, and especially acidic gases such as $\mathrm{HCl}$ and $\mathrm{HNO}_{3}$, have a great affinity for ice surface (see reviews by Abbatt, 2003 and Huthwelker et al., 2006). Several small molecules, such as $\mathrm{HCl}$ (Dominé et al., 1994; Thibert and Dominé, 1997), $\mathrm{HNO}_{3}$ (Thibert and Dominé, 1998), HCHO (Perrier et al., 2003; Barret et al., 2011b), and $\mathrm{H}_{2} \mathrm{O}_{2}$ (Sigg et al., 1992, and references therein; Conklin et al., 1993; Jacob and Klockow, 1993; McConnell et al., 1997b), form solid solutions in ice. Thus, solid-state diffusion is able to either bury these molecules in the inner part of snow crystals or, conversely, make these molecules available for (photo)chemical reactions at the surface after migration from the bulk crystal.

Another physical process, known as co-condensation, is the simultaneous condensation of water vapour and trace gases at the air-ice interface. Water vapour fluxes in the snowpack are mainly driven by temperature gradients, leading to massive mass transfer from the warmest snow layers, which sublimate, towards the coldest parts, where vapour condenses (Calonne et al., 2014; Ebner et al., 2015; Hansen and Foslien, 2015). More generally, the subsequent change in snow morphology, called temperature gradient metamorphism, affects the whole snowpack following seasonal temperature variations (Marbouty, 1980; Sommerfeld, 1983; Flin and Brzoska, 2008; Pinzer and Schneebeli, 2009; Pinzer et al., 2012; Ebner et al., 2015), and particularly the upper part of the snowpack subjected to the diurnal temperature cycle (Picard et al., 2012; Champollion et al., 2013, and references therein). Indeed, high crystal growth rates are observed at the surface of the snowpack, and up to $10 \mathrm{~cm}$ under the snow surface (Colbeck, 1989, their Fig. 8) though the exact depth is subject to debate (Brandt and Warren, 1993; Kuipers Munneke et al., 2009; Libois et al., 2014). Along with the vapour flux, trace impurities present in the interstitial air, or temporarily adsorbed on the ice surface, might be incorporated in the crystals (Conklin et al., 1993; Bales et al., 1995; Dominé and Thibert, 1996; Xueref and Dominé, 2003; Dominé and Rauzy, 2004; Kärcher and Basko, 2004; Ullerstam and Abbatt, 2005; Kärcher et al., 2009). This kinetic process of incorporation is much more efficient than air-ice thermodynamic equilibrium, which probably explains why measured concentrations have sometimes been shown to be of out of equilibrium (Bales et al., 1995; Dominé and Thibert, 1995, 1996; Ullerstam and Abbatt, 2005).

\subsection{Nitrate sinks and sources}

As regards the snow composition, nitrate sinks are either the photolysis or physical release processes (desorption, sublimation), sometimes referred to as volatilisation or evaporation. An early study by Röthlisberger et al. (2002) concluded that the nitrate photolysis is the major loss process. A recent work from Erbland et al. $(2013,2015)$ confirmed that the denitrification of the snowpack by means of physical release is negligible compared to the photochemical loss process. Thus, as regards the air composition above the snow, the nitrate photolysis occurring in the snow is the main source of $\mathrm{NO}_{x}$. The models of snow chemistry developed so far mainly intend to reproduce field measurements of $\mathrm{NO}_{x}$ fluxes emitted by the snowpack. Thus, they focus on snowto-air exchange processes driven by (photo)chemistry. However, air-to-snow physical exchange processes have been ignored in several studies (Boxe and Saiz-Lopez, 2008; Bock and Jacobi, 2010). In other models, these physical processes were bypassed through ad hoc parameterisation and/or implemented using air-liquid equilibrium following Henry's law, based on the assumption that snow crystals are covered by a liquid layer (Liao and Tan, 2008; Thomas et al., 2011; Toyota et al., 2014).

These modelling approaches and their pitfalls were discussed in detail by Dominé et al. (2013). One of the problems of these models is that ignoring or using inappropriate parameterisations for air-to-snow uptake processes implies that the snow behaves mostly as an initial reservoir of chemical species but does not replenish properly. This implicit assumption can be correct when focusing on the fluxes emitted 


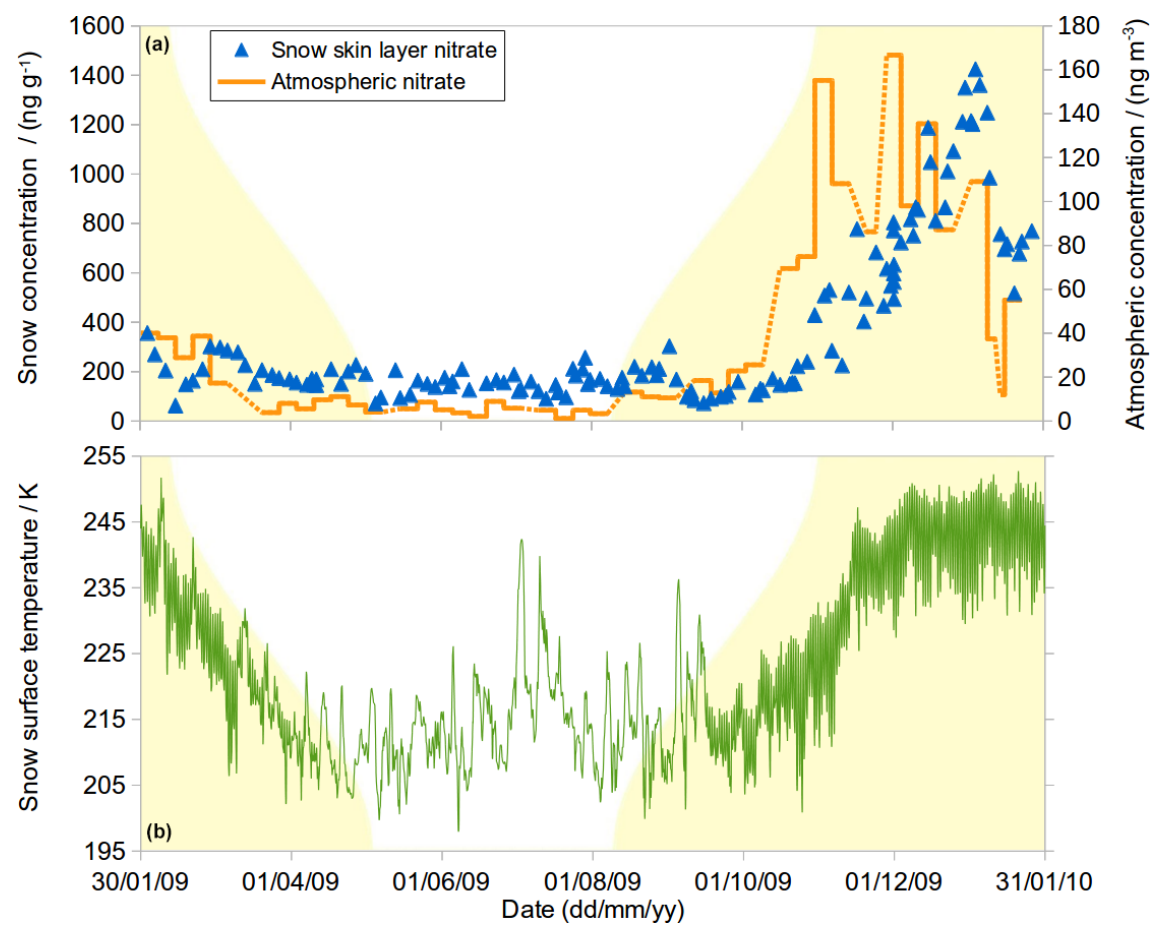

Figure 1. (a) Atmospheric nitrate concentration (orange lines, right axis) and snow skin layer nitrate concentration (blue triangles, left axis). (b) Modelled surface snow temperature. In both panels, the yellow background area is proportional to sunlight duration.

by the snowpack over a short period of time but is unable to accurately describe the evolution of the snow composition (Dominé et al., 2013). The most striking example to illustrate the importance of air-to-snow uptake processes is revealed by the yearly pattern of nitrate concentration in surface snow (see Fig. 1a). It is now well documented that the nitrate concentration in the surface snow exhibits a seasonal peak during summer on the Antarctic Plateau, when the solar flux is close to its annual maximum and photolysis is strongest (Erbland et al., 2013, and references therein). This implies that uptake processes counteract photochemical loss and thus need to be studied in order to understand the nitrate budget of the snow. Additional evidence that snow composition is strongly linked to physical processes is shown by a recent study by Jones et al. (2014). Measurements of gaseous $\mathrm{HNO}_{3}$ were carried out with a high temporal resolution of $10 \mathrm{~min}$, during 4 winter months at Halley station, located on the Antarctic coast. This work reveals that $\mathrm{HNO}_{3}$ concentration is strongly correlated $\left(R^{2}=0.70\right)$ with the temperature, emphasising that physical air-snow exchange processes play a key role during this period of the year.

As far as we are aware, the only physically based modelling studies of air-snow exchange processes were carried out in the late 1990s to interpret multi-year firn concentration profiles of $\mathrm{H}_{2} \mathrm{O}_{2}$ (McConnell et al., 1997a, b, 1998) and HCHO (Hutterli et al., 1999, 2002). Both of these series of modelling studies dealt with air-snow uptake/release through an exchange coefficient accounting for a Henry's law type partitioning between the two compartments (Hutterli et al., 2003, their Fig. 1). More recently, Barret et al. (2011a) proposed an air-snow exchange model to reproduce surface snow HCHO concentration. In that study, the surface snow is depicted as a unique spherical, layered grain whose surface concentration of $\mathrm{HCHO}$ is constrained by the airice thermodynamic equilibrium. Their model uses the measured gas-phase $\mathrm{HCHO}$ concentration as input and solves the spherical diffusion equation with radial symmetry to calculate the mean concentration in the whole snow grain. Their results reproduce the concentration measured in surface snow during a $36 \mathrm{~h}$ intensive sampling period in the course of the OASIS 2009 campaign with fairly good agreement (Barret et al., 2011a, their Fig. 4).

\subsection{A process-resolving model for air-snow exchange of nitric acid}

For the first time, we propose a process-resolving model for air-snow exchange of nitric acid $\left(\mathrm{HNO}_{3}\right)$, which allows for an investigation of the above-mentioned physicochemical exchange processes. An in-depth investigation of the cocondensation process leads to the development of a physically based parameterisation of this process. Following a similar approach to that of Barret et al. (2011a), we consider a single spherical layered snow grain located in the uppermost $\sim 4 \mathrm{~mm}$ of the snowpack ("skin layer" hereinafter). This snow grain is assumed to be in direct contact with the 
air just above the snowpack, because the air in the skin layer pore-space rapidly equilibrates with the atmosphere. Using the atmospheric nitrate concentration measured at Dome C (DC) for about 1 year as input, the model calculates the snow nitrate concentration resulting from (i) adsorption on the snow grain surface, (ii) solubilisation into the outermost layer according to thermodynamic equilibrium and solid-state diffusion inside the snow grain, and (iii) co-condensation following vapour fluxes inside the upper snowpack. Model results are compared to year-round measurements of the skin layer nitrate concentration.

Based on the evidence that the photolysis sink is weaker than uptake processes (see Fig. 1a), we did not implement the photolysis process in our model. An estimation of the uptake flux of nitrate inferred from the developed parameterisation allows a comparison with photolysis loss flux. This analysis confirms that the photolysis is negligible in the skin layer due to the very strong temperature gradient driving an intense condensation flux.

The input datasets are presented in the next section, and the model is described in Sect. 3. The results obtained in configuration 1 (adsorption only) are presented and discussed in Sect. 4, and those relative to the model configuration 2 (solidstate diffusion) are presented in Sect. 5 .

\section{Input data description}

\subsection{Annual atmospheric and skin layer nitrate concentrations at Dome $\mathbf{C}$}

\subsubsection{Atmospheric nitrate}

Atmospheric nitrate, which includes both particulate nitrate and gaseous $\mathrm{HNO}_{3}$, was measured continuously at DC between January 2009 and January 2010 using a highvolume air sampler placed $5 \mathrm{~m}$ above the snow surface (Erbland et al., 2013). Atmospheric nitrate was collected on glass fibre filters, which efficiently trap both particulate nitrate and gaseous $\mathrm{HNO}_{3}$ (Frey et al., 2009; Erbland et al., 2013). Atmospheric nitrate was quantitatively extracted in $40 \mathrm{~cm}^{3}$ of ultrapure water via centrifugation using Millipore Centricon $^{\mathrm{TM}}$ filter units, and its concentration was then determined using the colorimetric method as described in Erbland et al. (2013). Atmospheric nitrate concentration was calculated as the ratio of the total $\mathrm{NO}_{3}^{-}$filter loading to the total volume of air pumped through the filter at standard temperature and pressure conditions and expressed in $\mathrm{ng} \mathrm{m}^{-3}$.

Atmospheric nitrate samples were collected for 37 separate 5-7-day periods (see Fig. 1a). Over the year, 10 samples were dedicated to ${ }^{35} \mathrm{~S}$ measurement. The missing values were linearly interpolated (dashed lines in Fig. 1a). As can be seen in Fig. 1a, atmospheric nitrate concentration is low and steady, with a mean value of $(8.2 \pm 5.1) \mathrm{ng} \mathrm{m}^{-3}$ from March to September, followed by a sharp increase during spring (av- erage value of $(98.5 \pm 39.7) \mathrm{ng} \mathrm{m}^{-3}$ from October to December, with peak values greater than $130 \mathrm{ng} \mathrm{m}^{-3}$ ). A rapid decrease is observed in early summer. This yearly pattern is in good agreement with previous measurements performed at DC between January 2007 and January 2008 (Frey et al., 2009).

A few simultaneous measurements of atmospheric nitrate (also reported as "filterable nitrate", $\mathrm{f}-\mathrm{NO}_{3}^{-}$) and $\mathrm{HNO}_{3}$ give further insight into the partitioning between both. Arimoto et al. (2008, their Fig. 5) and Davis et al. (2008, their Fig. 3) report concurrent measurements of $\mathrm{f}-\mathrm{NO}_{3}^{-}$and $\mathrm{HNO}_{3}$ carried out during 23 days in the course of the ANTCI campaign, at South Pole. Atmospheric nitrate was measured in a very similar way as at DC, using a high-volume air sampler with Whatman $41^{\mathrm{TM}}$ filters, which have been shown to efficiently collect atmospheric nitrate as well (Arimoto et al., 2008, and references therein). This dataset reveals that $\mathrm{HNO}_{3}$ accounts for the major part of the atmospheric nitrate over the whole period of measurements, and we calculated an average proportion of $80 \%$ of $\mathrm{HNO}_{3}$ among total $\mathrm{f}^{-\mathrm{NO}_{3}^{-}}$(Davis et al., 2008, their Fig. 3).

Over the 2009-2010 period, $\mathrm{HNO}_{3}$ was measured at DC using annular denuder tube, with 48 sampling periods of 2.5 days on average (B. Jourdain and M. Legrand, personal communication, 2012). These different sampling periods between the datasets hinder our ability to make a close comparison, but it is obvious that both time series show very good agreement (data not shown). The ratio of $\mathrm{HNO}_{3}$ to atmospheric nitrate is of the same order as that obtained at South Pole.

Another recent study has presented a multi-year record of particulate nitrate at DC, collected on low volume sampler with Teflon filters (Traversi et al., 2014). Both the absolute nitrate concentration and the overall temporal pattern reported in that study are in good agreement with those of Erbland et al. (2013). By comparing the measurements of an eight-stage impactor along with those provided by a $\mathrm{PM}_{10}$ device, the authors concluded that, during late summer (January and February), only $12.5 \%$ of atmospheric nitrate is collected on $\mathrm{PM}_{10}$ PTFE filters, while this fraction reaches $30 \%$ for November and December. Thus, a more extensive characterisation of the temporal variation in the partitioning between gaseous $\mathrm{HNO}_{3}$ and particulate nitrate is needed to accurately retrieve $\mathrm{HNO}_{3}$ concentration from atmospheric nitrate measurements.

To conclude, atmospheric nitrate measured at DC during several years using different methods shows a very consistent and reproducible temporal pattern. Comparisons between gaseous and particulate fractions indicate that $\mathrm{HNO}_{3}$ accounts for the major part of atmospheric nitrate. Thus, any atmospheric processes related to aerosol deposition are likely to be of minor importance or negligible, and are not accounted for in this study. For the sake of simplicity, we assume hereafter that the concentration of gaseous $\mathrm{HNO}_{3}$ used as input in our model is equal to the concentration of at- 
mospheric nitrate. This assumption will be further discussed along with the results of the model.

\subsubsection{Snow nitrate}

Nitrate concentration was measured year-round between 2008 and 2010 during the NITE DC (NITrate Evolution in surface snow at Dome C) programme. The skin layer (estimated average thickness of $(4 \pm 2) \mathrm{mm})$ was sampled once or twice a day during summer, and about once a week during winter (Erbland et al., 2013). The uncertainty ascribed to spatial variability and sampling method is estimated to be $20 \%$. In this study, we only used data from 30 January 2009 to 31 January 2010 published by Erbland et al. (2013, their Fig. 6), which are reproduced in Fig. 1a. $\mathrm{NO}_{3}^{-}$concentration in the skin layer exhibits a seasonal pattern similar to that of atmospheric nitrate: it remains relatively low and steady during winter, with an average value of $(161 \pm 50) \mathrm{ng} \mathrm{g}^{-1}$ during the polar night, i.e. from March to September. Thereafter, a sharp increase occurs around mid-November, with concentration in the $600-1400 \mathrm{ng} \mathrm{g}^{-1}$ range. The temporal lag of 3-4 weeks between the atmospheric and skin layer variations indicates a complex air-snow transfer function that this work aims at elucidating by developing a process-resolving model.

These temporal variations in $\mathrm{NO}_{3}^{-}$observed in DC surface snow are also similar to the general trends featured by previous measurements in surface snow made at Halley station in coastal Antarctica from March 2004 to February 2005 (Wolff et al., 2008; Jones et al., 2011).

\subsection{Snowpack physical properties}

\subsubsection{Snow temperature}

Snow temperature is a key parameter for modelling snow chemistry since all processes involved in snow chemical exchange are temperature-dependent. In addition, snow metamorphism and water vapour flux depend on temperature as well as on the vertical gradient of the temperature profile (see, for instance, Marbouty, 1980; Sommerfeld, 1983; Colbeck, 1989; Flin and Brzoska, 2008). We used modelled data to get snow surface temperature over the whole year of nitrate measurements.

A snowpack thermal diffusion model including a surface scheme coupled with a radiative transfer model to account precisely for the absorption of the radiation inside the snowpack is used (Picard et al., 2012). The snowpack is discretised in horizontally homogeneous layers whose thickness exponentially increases with depth. The model takes meteorological forcing from ERA-Interim reanalysis as input and computes the evolution of the temperature profile (Picard et al., 2009). Predictions were successfully compared to daily passive microwave satellite data over the continent, and the comparison with Brun et al. (2011) results shows good skill.
We used the modelled temperature in the uppermost $3 \mathrm{~mm}$ thick layer (which is also the surface "skin" temperature used in the surface energy budget calculation) and apply linear interpolation to down-scale the hourly data to $10 \mathrm{~min}$, the time step of our model. The modelled snow surface temperature is shown in Fig. 1b.

We compared the modelled temperature with the skin temperature deduced from the upwelling longwave radiation observations from the BSRN (Baseline Surface Radiation Network; Christian Lanconelli, personal communication, 2011; see Supplement Sect. S1). From this 3 month data set (from November 2009 to January 2010, raw data), the comparison revealed a small warm bias of the model $(\sim 2.5 \mathrm{~K})$, and a slight underestimation of the amplitude of the diurnal cycle (see Supplement Sect. S1) which agrees with other studies using ERA-Interim (Fréville et al., 2014). However, since this comparison was only possible during the summer, the same discrepancies between modelled and measured temperatures would not necessarily hold in winter.

\subsubsection{Specific surface area}

In our model, the physical description of the snow mainly relies on the snow specific surface area (SSA) value, which directly affects exchanges through the air-snow interface (see, for example, Dominé et al., 2008). Assuming spherical grains, the radius follows the relation

$R=\frac{3}{\operatorname{SSA} \rho_{\text {ice }}}$,

where $R$ is the radius (in $\mathrm{m}$ ), SSA is the snow specific surface area (in $\mathrm{m}^{2} \mathrm{~kg}^{-1}$ ), and $\rho_{\text {ice }}$ is the ice density, with $\rho_{\text {ice }} \simeq$ $924 \mathrm{~kg} \mathrm{~m}^{-3}$ (Hobbs, 1974 , at $-50^{\circ} \mathrm{C}$, DC annual mean temperature). When this study was initiated, the only SSA value reported at DC was $38.1 \mathrm{~m}^{2} \mathrm{~kg}^{-1}$ for the first centimetre, decreasing monotonically to $13.6 \mathrm{~m}^{2} \mathrm{~kg}^{-1}$ at $70 \mathrm{~cm}$ depth (Gallet et al., 2011, their Fig. 4 and Table A1). Recent work specifically studying surface hoar at DC reported very close values, with an average of $39.0 \mathrm{~m}^{2} \mathrm{~kg}^{-1}$ for the top centimetre of snow and $26.4 \mathrm{~m}^{2} \mathrm{~kg}^{-1}$ for the second centimetre (Gallet et al., 2014). Thus, SSA was set to a value of $38.1 \mathrm{~m}^{2} \mathrm{~kg}^{-1}$ by default in the model, leading to a grain radius $R=85 \mu \mathrm{m}$. Recently, Libois et al. (2015) and Picard et al. (2016) investigated seasonal variations in SSA at DC showing that these values are typical of the summer while 2 to 3 -fold higher values are observed in winter. The effect of changing SSA was further tested in a sensitivity test presented in Sect. 5.4. 


\section{Model description}

\subsection{From gaseous $\mathrm{HNO}_{3}$ to solid solution of nitrate in snow}

A brief summary of the current knowledge about solvation steps which lead gaseous $\mathrm{HNO}_{3}$ to form solid solution in bulk ice is presented in this section.

The uptake of trace gases on ice, and more specifically of acidic gases among which $\mathrm{HNO}_{3}$, has been the subject of numerous investigations (see reviews by Abbatt, 2003; Huthwelker et al., 2006). Conceptually, this uptake proceeds firstly by molecular adsorption of $\mathrm{HNO}_{3}$, followed by the ionisation (or dissociation) and then progressive solvation at the surface leading to a partial solvation shell (Buch et al., 2002; Bianco et al., 2007, 2008). In a second stage, thought to be much slower, the adsorbed nitrate anions sink into the innermost crystal layers, leading to a complete solvation shell, and diffuse towards the bulk crystal. Recent studies have addressed the ionisation state of $\mathrm{HNO}_{3}$ adsorbed on ice surface, either by using surface sensitive spectroscopy techniques (Křepelová et al., 2010; Marchand et al., 2012; Marcotte et al., 2013, 2015) or through molecular dynamics models (Riikonen et al., 2013, 2014). Molecular adsorbed state is found to be metastable, which happens only at very low temperatures $(45 \mathrm{~K})$, whilst ionic dissociation irreversibly occurs upon heating at $120 \mathrm{~K}$ (Marchand et al., 2012). Molecular dynamics simulations suggest a pico- and subpicosecond ionisation of $\mathrm{HNO}_{3}$ in the defect sites (Riikonen et al., 2013), further supporting the idea that molecular adsorption of $\mathrm{HNO}_{3}$ on ice is a fleeting state prior to ionisation, at least for environmentally relevant temperatures.

Despite these recent improvements in the understanding of $\mathrm{HNO}_{3}$ ionisation following adsorption on an ice surface, the transition between surface (adsorption) and bulk (diffusion) processes still needs to be fully characterised. To the best of our knowledge, no process-scale parameterisation of the dissociation/solvation exists at the moment. Such parameterisation would be necessary to link surface and bulk concentrations, and further studies are thus needed to fully characterise the transition between these states. For this reason, both processes were treated separately in our model. Model configuration 1 (adsorption) is described in the next section, while configuration 2 (solid-state diffusion) is described in Sect. 3.3.

\subsection{Model configuration 1: adsorption}

The $\mathrm{HNO}_{3}$ surface coverage is a function of temperature and pressure only. Crowley et al. (2010) presented a compilation of data evaluated by a IUPAC subcommittee that characterises heterogeneous processes on the surface of solid particles, including ice. They recommend the use of a single-site Langmuir isotherm which gives the fractional surface cover- age $\theta$ :

$\theta=\frac{N}{N_{\max }}=\frac{K_{\mathrm{LangP}} P_{\mathrm{HNO}_{3}}}{1+K_{\mathrm{LangP}} P_{\mathrm{HNO}_{3}}}$,

where $N_{\max }=2.7 \times 10^{18}$ molecules $\mathrm{m}^{-2}$ is the $\mathrm{HNO}_{3}$ surface coverage at saturation,

$K_{\text {LangP }}=\frac{K_{\text {LinC }} \mathcal{N}_{\mathrm{A}}}{N_{\max } \mathcal{R} T}\left(\right.$ in $\left.\mathrm{Pa}^{-1}\right)$,

$K_{\mathrm{LinC}}=7.5 \times 10^{-7} \exp \left(\frac{4585}{T}\right)$ (in m).

$K_{\text {LangP }}$ and $K_{\text {LinC }}$ are partition coefficients expressed in different units, $N$ is the $\mathrm{HNO}_{3}$ surface coverage (in molecules $\mathrm{m}^{-2}$ ), $P_{\mathrm{HNO}_{3}}$ is the $\mathrm{HNO}_{3}$ partial pressure (in $\mathrm{Pa}$ ), $\mathcal{N}_{\mathrm{A}}$ is the Avogadro constant, $T$ is snow temperature (in $\mathrm{K}$ ), and $\mathcal{R}$ is the molar gas constant $\left(\mathcal{R}=8.314 \mathrm{~J} \mathrm{~K}^{-1} \mathrm{~mol}^{-1}\right)$.

This parameterisation is established for temperatures ranging from 214 to $240 \mathrm{~K}$, which is almost adequate for DC temperatures, typically in the $200-250 \mathrm{~K}$ range (see Fig. 1b). The conversion of surface coverage to bulk concentration is done using SSA:

$\left[\mathrm{HNO}_{3}\right]=\frac{N \times \mathrm{SSA}}{\mathcal{N}_{\mathrm{A}}}$,

where $\left[\mathrm{HNO}_{3}\right]$ is the nitrate concentration (in $\mathrm{mol} \mathrm{m}^{-3}$ ).

The results and discussion following adsorption calculation are presented in Sect. 4.

\subsection{Model configuration 2: solid-state diffusion}

In configuration 2 , the model computes solid-state diffusion in a layered snow grain. The outermost layer concentration or boundary condition (BC) is successively set according to three distinct parameterisations. Firstly, the $\mathrm{NO}_{3}^{-}$concentration at the air-ice interface is set according to thermodynamic equilibrium (BC1). In a second stage, the kinetic, cocondensation process is taken into account through an empirical, diagnostic parameterisation (BC2). Then, using the results from the previous $\mathrm{BCs}$, a physically based prognostic parameterisation is developed (BC3). The general diffusion scheme and specific BCs are presented in the next sections.

\subsubsection{Diffusion scheme}

In configuration 2 , the model considers a spherical snow grain with a radius $R=85 \mu \mathrm{m}$, divided in concentric layers of constant thickness $\delta R=0.05 \mu \mathrm{m}$. The model computes the solid-state diffusion equation in spherical geometry with radial symmetry in the snow grain:

$\frac{\partial C(r, t)}{\partial t}=D\left(\frac{2}{r} \frac{\partial C(r, t)}{\partial r}+\frac{\partial^{2} C(r, t)}{\partial r^{2}}\right)$,

where $C(r, t)$ is nitrate concentration in the layer of radius $r$ at time $t$ and $D$ is the diffusion coefficient of $\mathrm{HNO}_{3}$ in ice 
provided by Thibert and Dominé (1998):

$D=1.37 \times 10^{-4} \times 10^{-2610 / T}\left(\right.$ in $\left.^{2} \mathrm{~s}^{-1}\right)$.

The modelled snow surface temperature ranges from 198 to $253 \mathrm{~K}$ (average $222 \mathrm{~K}$ ) during the studied period. The diffusion coefficient thus ranges from $8.9 \times 10^{-18}$ to $6.4 \times$ $10^{-15} \mathrm{~m}^{2} \mathrm{~s}^{-1}$ (average $7.1 \times 10^{-16} \mathrm{~m}^{2} \mathrm{~s}^{-1}$ ). A characteristic time for diffusion, $\tau$, can be estimated as $\tau=l^{2} / D$, where $l$ is a characteristic diffusion length. Considering the spherical geometry of the snow grain, when diffusion reaches $0.21 \times R$, $50 \%$ of the volume is affected, and when diffusion reaches $0.37 \times R, 75 \%$ of the volume is affected. Using these values as characteristic diffusion length and the average diffusion coefficient, the characteristic times for diffusion are $\tau_{.50} \simeq 5$ days and $\tau_{.75} \simeq 16$ days.

Thibert and Dominé (1998) indicated an uncertainty of $\pm 60 \%$ for the diffusion coefficient, further explaining that it is probably the upper limit because of the possible faster diffusion through linear crystal defects or grain boundaries. The study by Thibert and Dominé (1998) was carried out at temperatures ranging from -8 to $-35^{\circ} \mathrm{C}$. Nevertheless, Eq. (7) is applied to the temperatures of DC surface snow, potentially leading to an additional uncertainty.

The concentration of the outermost layer of the modelled snow grain, which is the BC of the diffusion equation (Eq. 6), was successively parameterised in three different ways, which are detailed in the next sections.

\subsubsection{Equilibrium boundary condition (BC1)}

In a first attempt labelled $\mathrm{BC} 1$, the outermost layer concentration was set according to the thermodynamic equilibrium solubility of $\mathrm{HNO}_{3}$ in solid solution as measured by Thibert and Dominé (1998):

$X_{\mathrm{HNO}_{3}}^{0}=2.37 \times 10^{-12} \exp \left(\frac{3532.2}{T}\right) P_{\mathrm{HNO}_{3}}^{1 / 2.3}$,

where $X_{\mathrm{HNO}_{3}}^{0}$ is the molar fraction of $\mathrm{HNO}_{3}$ in ice, $T$ is the snow temperature (in $\mathrm{K}$ ), and $P_{\mathrm{HNO}_{3}}$ is the $\mathrm{HNO}_{3}$ partial pressure (in $\mathrm{Pa}$ ).

Thibert and Dominé (1998) indicated an uncertainty of $\pm 20 \%$ for equilibrium solubility. As with the diffusion coefficient, Eq. (8) is also applied to DC surface snow temperatures, potentially leading to an additional uncertainty.

The results and discussion of the modelling of nitrate concentration in surface snow using this BC1 approach are presented in Sect. 5.1. We also investigated how the uncertainties over the solubility and the diffusion coefficient affect the simulations, in a sensitivity study presented in Sect. 5.4.

\subsubsection{Diagnostic co-condensation parameterisation (BC2)}

To investigate the concentration of the growing phase, an empirical, diagnostic parameterisation of the co-condensation process was firstly developed.
Valdez et al. (1989) carried out experiments on $\mathrm{SO}_{2}$ incorporation into ice growing from water vapour and reported that the amount of sulfur incorporated into the ice increased linearly with the amount of ice deposited. Jacob and Klockow (1993) compared the concentration of $\mathrm{H}_{2} \mathrm{O}_{2}$ in the gas phase and in snow during fog events and showed that the molar fraction of hydrogen peroxide, $\mathrm{X}_{\mathrm{H}_{2} \mathrm{O}_{2}}$, resulting from co-condensation was similar to the ratio of partial pressures: $X_{\mathrm{H}_{2} \mathrm{O}_{2}} \simeq \frac{P_{\mathrm{H}_{2} \mathrm{O}_{2}}}{P_{\mathrm{H}_{2} \mathrm{O}}}$, as previously hypothesised by Sigg and Neftel (1988). Dominé et al. (1995) refined this analysis using the kinetics theory of gases to include the number of collisions, and further taking into account the surface accommodation coefficients $\alpha$. They proposed that the molar fraction of a gas $i\left(X_{i}\right)$ condensing along with water vapour should obey the following equation, where $M$ is the molar mass:

$X_{i}=\frac{P_{i}}{P_{\mathrm{H}_{2} \mathrm{O}}} \frac{\alpha_{i}}{\alpha_{\mathrm{H}_{2} \mathrm{O}}} \sqrt{\frac{M_{\mathrm{H}_{2} \mathrm{O}}}{M_{i}}}$.

However, Ullerstam and Abbatt (2005) carried out laboratory measurements of $\mathrm{HNO}_{3}$ concentration in growing ice, and their results suggested that $\mathrm{HNO}_{3}$ concentration was proportional to $P_{\mathrm{HNO}_{3}}^{0.56}$ and independent of the water vapour partial pressure:

$\log _{10}\left(X_{\mathrm{HNO}_{3}}\right)=0.56 \times \log _{10}\left(P_{\mathrm{HNO}_{3}}\right)-3.2$,

where the factor 0.56 could be explained by acid dissociation during co-condensation. Another possible explanation proposed by Ullerstam and Abbatt (2005) is that thermodynamic solubility governs at least partially the composition of a growing crystal as $\mathrm{HNO}_{3}$ is sufficiently volatile and mobile to be excluded from the growing ice. Indeed, the power 0.56 dependence to $\mathrm{HNO}_{3}$ partial pressure is close to that of thermodynamic equilibrium solubility (in Eq. 8, 1/2.3 0.43 ).

To summarise the conclusions of these studies, the cocondensed phase has a concentration which depends on (i) the studied trace gas partial pressure (but without agreement on the exponent in the case of $\mathrm{HNO}_{3}$ ) and (ii) may or may not depend on the water vapour partial pressure. Thus, in order to test these hypotheses, a first simple diagnostic parameterisation of co-condensation process was implemented by adding an adjustable term to prescribe the outermost layer concentration (BC2):

$X_{\mathrm{HNO}_{3}}=X_{\mathrm{HNO}_{3}}^{0}+\alpha \times P_{\mathrm{HNO}_{3}}^{\beta} \times P_{\mathrm{H}_{2} \mathrm{O}}^{\gamma}$,

where $X_{\mathrm{HNO}_{3}}^{0}$ is the molar fraction of $\mathrm{HNO}_{3}$ in ice given by thermodynamic equilibrium (see Eq. 8), $P_{\mathrm{HNO}_{3}}$ and $P_{\mathrm{H}_{2} \mathrm{O}}$ are partial pressures of $\mathrm{HNO}_{3}$ and water vapour, respectively (in $\mathrm{Pa}$ ), and $\alpha, \beta$, and $\gamma$ are adjustable parameters. Solid-state diffusion within the layered snow grain then proceeds as previously described (Sect. 3.3.1). The results of this BC2 configuration are presented in Sect. 5.2. 


\subsubsection{Prognostic co-condensation parameterisation (BC3)}

In order to develop a physically based, prognostic parameterisation of the co-condensation process (BC3), two questions need to be answered: how much water vapour condenses on the snow grain, and how much nitrate actually co-condenses along with the water vapour.

The first question is closely related to the growth rate of snow crystals undergoing a temperature gradient. Calculation of the water vapour gradient inside the snowpack is a complex matter (Flin and Brzoska, 2008). Using upscaling theories, several recent studies aimed at obtaining macroscopic parameterisations ensued from an accurate description of the processes (heat conduction, vapour diffusion, sublimation, and condensation) occurring at the microscopic scale (Miller and Adams, 2009; Pinzer et al., 2012; Calonne et al., 2014; Hansen and Foslien, 2015). A major issue may arise when simply upscaling microscopic laws by using averaged, macroscopic parameters such as the temperature gradient. Indeed, as illustrated by Calonne et al. (2014, their Fig. 4), microscale inhomogeneities are likely to enhance the local temperature gradient, and thus the flux of water vapour. However, Pinzer et al. (2012) compared the mass flux calculated using a macroscopic diffusion law on the one hand and two microscopic computations (particle image velocimetry and finite-element simulation) on the other. They concluded that "the three methods of calculation coincide reasonably well", and thus that "the macroscopic vapour flux in snow can be calculated once the temperature gradient and the mean temperature of the snow are known, independently of the microstructure". In the macroscopic diffusion law equation, Pinzer et al. (2012, their Eq. 3) used an effective diffusion coefficient for water vapour in the interstitial air, whose value has been a subject of debate for a long time (Calonne et al., 2014, and references therein). In their study, Calonne et al. (2014) concluded that the effective vapour diffusion is not enhanced in snow.

Based on these results, we assumed that a macroscopic scale water vapour flux can be reasonably estimated using macroscopic, mean parameters. Following particulate growth laws in cloud models, Flanner and Zender (2006) proposed an equation giving the mass variation over time as a function of the water vapour gradient:

$$
\frac{\mathrm{d} m}{\mathrm{~d} t}=4 \pi R^{2} D_{\mathrm{v}}\left(\frac{\mathrm{d} \rho_{\mathrm{v}}}{\mathrm{d} x}\right)_{x=R},
$$

where $R$ is the particle radius, $D_{\mathrm{v}}$ is the diffusivity of water vapour in air, and $\rho_{\mathrm{v}}$ is the water vapour density (in $\mathrm{kg} \mathrm{m}^{-3}$ ). The diffusivity of water vapour in air can be found in Pruppacher and Klett (1997) as a function of pressure and temperature, in the -40 to $+40{ }^{\circ} \mathrm{C}$ range:

$D_{\mathrm{v}}=2.11 \times 10^{-5}\left(\frac{T}{T_{0}}\right)^{1.94} \frac{P_{0}}{P}\left(\right.$ in $\left.^{2} \mathrm{~s}^{-1}\right)$, where $T_{0}=273.15 \mathrm{~K}$ and $P_{0}=101325 \mathrm{~Pa}$. We stress here that the water vapour gradient in Eq. (12) was originally intended to be the local microscopic gradient, but the macroscopic gradient derived from the modelled temperature profile in the two uppermost layers was used here. Because this growth law is used to parameterise the co-condensation process, only the cases leading to mass increase were taken into account. Finally, the mass growth rate defined by Eq. (12) can be converted into volume growth rate using ice density $\rho_{\text {ice }}$, and then to radius growth $\Delta R$ (in $\mathrm{m}$ ) by assuming uniform condensation on the whole grain surface during a time step $\Delta t$ :

$$
\Delta R=\sqrt[3]{\frac{3}{4 \pi}\left(\frac{1}{\rho_{\text {ice }}} 4 \pi R^{2} D_{\mathrm{v}}\left(\frac{\Delta \rho_{\mathrm{v}}}{\Delta x}\right)_{x=R} \Delta t\right)+R^{3}}-R .
$$

Note that in this equation $\Delta R$ depends on $\Delta t^{1 / 3}$.

An accurate modelling of temperature gradient metamorphism and ensuing co-condensation process would require a complex description of the system, including snow grain shape, direction of growth, and local inhomogeneities, which is within the purview of snow microphysics 2-D or even 3-D state-of-the-art models (see, for example, Flin et al., 2003; Kaempfer and Plapp, 2009; Calonne et al., 2014). However, for the purpose of simplification, the dynamic feature of a growing crystal is implemented into a spherical grain whose radius is kept constant, as described hereafter.

The second question of the nitrate concentration in the growing phase presents a difficulty from the competition between co-condensation and diffusion. It was observed that the co-condensation process leads to concentrations that are out of thermodynamic equilibrium (Bales et al., 1995; Dominé and Thibert, 1995, 1996; Ullerstam and Abbatt, 2005) and enhance solid-state diffusion. The combination of these two processes was studied by Dominé and Thibert (1996), who proposed a theoretical description through a two-stage process. Firstly, a layer of thickness $\Delta R$ and composition $X_{\text {kin }}$ condenses at $t=0$. Then, solid-state diffusion takes place to re-equilibrate this layer towards the equilibrium concentration $X_{\mathrm{eq}}$, until another layer condenses at $t=\Delta t$, isolating the previous layer. According to this simplified description, the resulting molar fraction at a distance $d$ from the surface and after a diffusion time $t$ is given by

$X(d, t)=X_{\text {kin }}+\left(X_{\text {eq }}-X_{\text {kin }}\right) \operatorname{erfc}\left(\frac{d}{2 \sqrt{D t}}\right)$,

where $X_{\text {kin }}$ is the molar fraction of the growing phase (which could be provided either by the gas kinetics theory parameterisation, Eq. 9, or by the empirical relation, Eq. 10), $X_{\text {eq }}$ is the molar fraction inferred from thermodynamic equilibrium solubility (Eq. 8), and $D$ is the diffusion coefficient of $\mathrm{HNO}_{3}$ in ice (Eq. 7).

In Eq. (15), erfc is the complementary error function, where $\operatorname{erfc}(0)=1$ and $\operatorname{erfc}(x)$ is decreasing towards zero 


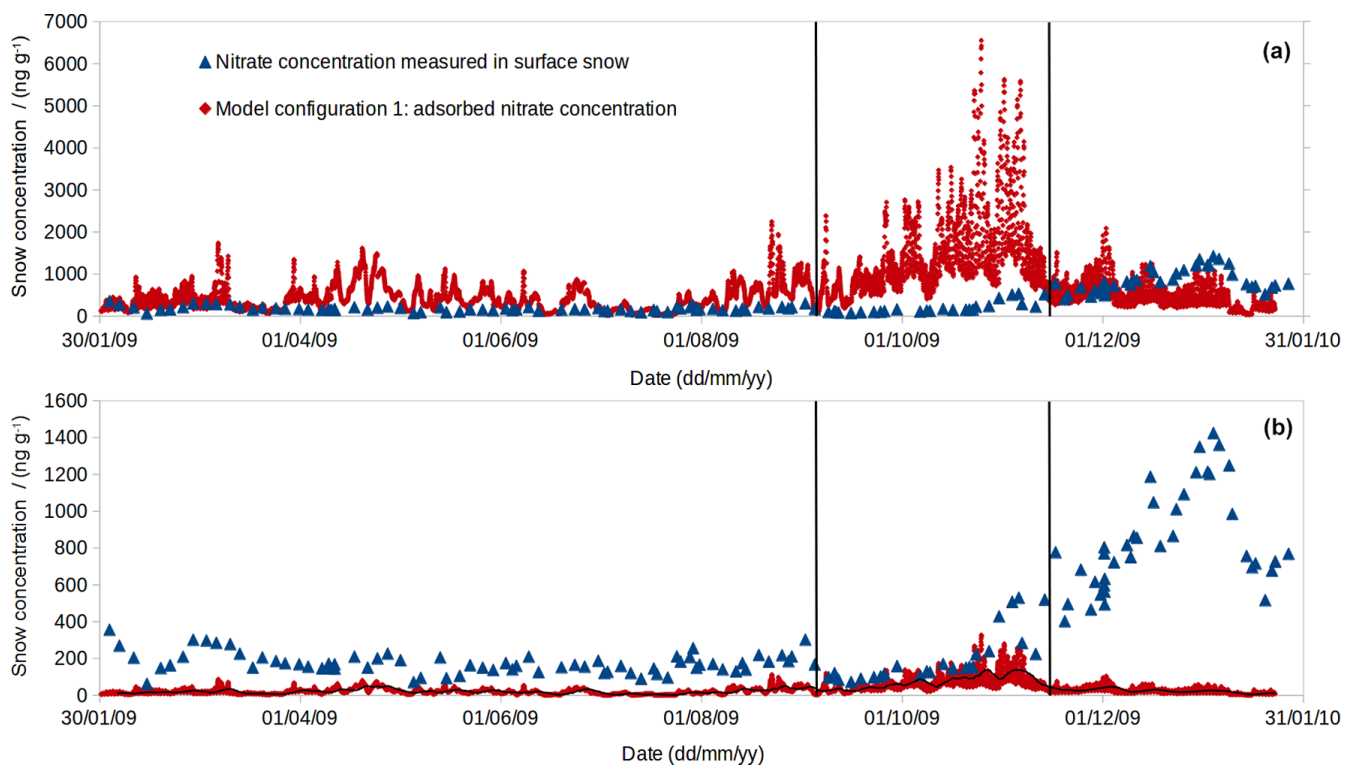

Figure 2. (a) Measured skin layer nitrate concentration (blue triangles) and modelled adsorbed concentration (red diamonds). The output time step is $1 \mathrm{~h}$. Vertical bars separate periods mentioned in the text. (b) Same as panel (a), with modelled adsorbed concentration reduced by a factor of 20 so that the envelope almost never exceeds the measured concentration. A running average (period $=5$ days) is displayed (black solid line). Note the $y$ axis scale change.

for positive values. Since $\sqrt{D t}$ represents the typical diffusion length over a time $t$, the resulting molar fraction given by Eq. (15) will be close to $X_{\text {eq }}$ if the condensed layer is thin compared to the typical diffusion length, i.e. if the layer rapidly re-equilibrates through diffusion. However, if the condensed layer is thick, the resulting molar fraction gets closer to $X_{\text {kin }}$.

Following Dominé and Thibert (1996), the BC3 boundary condition defining the outermost layer concentration is set as $X(\Delta R, \Delta t)$ (Eq. 15), where $\Delta R$ is the thickness of the condensed layer which has grown during the time step $\Delta t$ (Eq. 14). We emphasise that the radius of the modelled snow grain is kept unchanged along the whole simulation. The calculation of the radius increase due to the condensation of water vapour is only used to compute the concentration (Eq. 15) at the surface of the modelled snow grain $(\mathrm{BC})$.

\section{Results and discussions for model configuration 1}

The simulated nitrate concentration of the snow skin layer obtained in model configuration 1 , involving only the adsorption process, is presented and discussed in this section.

\subsection{Results}

The evolution of the concentration of nitrate in the snow skin layer is plotted in Fig. 2a. Undeniably, the adsorbed concentration modelled using non-dissociative Langmuir isotherms parameterisation does not fit with the measured concentration in three ways: firstly, the modelled concentration is higher than the measured ones during most of the year. From February to August, the average modelled concentration is 2.5 -fold higher than the measured one, and this ratio increases to 8.3 from September to mid-November (see vertical separations in Fig. 2a). However, the modelled concentration gradually decreases towards the end of January, while the measured one reaches a seasonal maximum, leading to a ratio of 0.62 between modelled and measured concentrations during this last period. Secondly, the modelled concentration shows a strong diurnal variability following temperature, with a ratio between daily maximum and minimum concentration regularly higher than 5 , and with a yearly average equal to 2.6. By contrast, field measurements show weak diurnal variations in nitrate concentration in surface snow and no anticorrelation with temperature (Fig. S2 in the Supplement). The third major discrepancy is a premature seasonal maximum in the computation, starting late August and reaching maximum early November, while concentration measured in snow lags by 65 days.

The features of the modelled concentration attributed to adsorbed nitrate can be explained by the temperature and partial pressure dependencies of the adsorption isotherm. The surface coverage parameterisation strongly decreases with temperature (exponential function of the reciprocal temperature in Eq. 4), whilst it increases roughly linearly with the $\mathrm{HNO}_{3}$ partial pressure when the surface coverage is well below saturation. This explains the strong diurnal variations following the temperature cycle. It also explains the yearly pattern of the modelled concentration: firstly, during the winter, very low temperature prevails over the low $\mathrm{HNO}_{3}$ partial 
pressures, leading to modelled concentration much higher than that measured. The influence of temperature is easily seen in April, May, and August, when temperature is the lowest (see Fig. 1b), leading to higher modelled concentration than in June and July, when temperature is higher and $\mathrm{HNO}_{3}$ partial pressure is alike. Then, from early September to early November, $\mathrm{HNO}_{3}$ partial pressure increases while temperature shows only a moderate increase, leading to the modelled peak of absorbed nitrate. Finally, nitrate partial pressure stays high until January, but this is counterbalanced by the temperature, which increases to its yearly maximum, forcing modelled surface coverage to fall well under the measured values.

\subsection{Discussion}

Despite the use of the current IUPAC recommendation for the parameterisation of $\mathrm{HNO}_{3}$ adsorption on ice, the modelled quantities adsorbed on snow are clearly incompatible with the measured concentration. In order to explain this discrepancy, we compared the experimental setups used in the various studies of adsorption (Abbatt, 1997; Arora et al., 1999; Hanson, 1992; Hudson et al., 2002; Hynes et al., 2002; Laird and Sommerfeld, 1995; Leu, 1988; Sokolov and Abbatt, 2002; Ullerstam et al., 2005; Zondlo et al., 1997). A review of these studies, and of the experimental techniques used, can be found in Huthwelker et al. (2006). In brief, two main experimental techniques prevail: flow tubes, which were used in most studies (Abbatt, 1997; Arora et al., 1999; Hanson, 1992; Hynes et al., 2002; Leu, 1988; Sokolov and Abbatt, 2002; Ullerstam et al., 2005), and Knudsen cells, which were used in two studies (Hudson et al., 2002; Zondlo et al., 1997). Whatever the technique used, ice was deposited on the reactor walls either by water vapour condensation (Hanson, 1992; Hudson et al., 2002; Leu, 1988; Zondlo et al., 1997) or by fast freezing of an ice film (Abbatt, 1997; Hynes et al., 2002; Sokolov and Abbatt, 2002; Ullerstam et al., 2005).

A first pitfall which may arise from these studies comes from the lack of quantification of the exposed surface area of ice, which was measured only once by Hudson et al. (2002). They carried out several experiments at 209, 213, and $220 \mathrm{~K}$ and found that the exposed surface was twice the geometrical surface. Leu et al. (1997) found that this ratio can be as high as $\sim 9$ in the case of ice formed by water vapour deposition at $196 \mathrm{~K}$. These authors also reported that this ratio increases with the amount of water deposited, as well as with decreasing temperature. On the other hand, in another study using ice formed by fast freezing of a film of water, Abbatt et al. (2008) concluded that the ice surface was smooth at a molecular level, implying a ratio near 1 . However, except in the study by Hudson et al. (2002), an underestimation of the exposed surface, which leads to an overestimation of the surface coverage of ice, cannot be ruled out.

All adsorption studies assumed that diffusion in bulk ice is negligible at very low temperature. However, even if the fraction of $\mathrm{HNO}_{3}$ entering the bulk ice is small, neglecting it leads to a systematic overestimation of the surface coverage. Cox et al. (2005) analysed the data in Ullerstam et al. (2005) to include the diffusion process. Their study brought new insight into surface vs. bulk processes, and their model performed well in reproducing adsorption curves when diffusion into the bulk was also taken into account. However, instead of using the existing parameterisation for nitrate solubility and diffusion coefficient in the ice (see Sect. 3.3.1 and 3.3.2), they made use of a simplified scheme to consider the diffusion process, which includes an adjustable rate coefficient for diffusion and hinders a close comparison with our parameterisation. Furthermore, the desorption curves could not be well fitted by their model, especially for low surface coverage, indicating that the processes involved are still not fully understood and constrained.

The diffusion of nitrate into bulk ice could also have been further enhanced for three distinct reasons. Firstly, it is worth noting that if the exposed surface area of ice is larger than the geometric surface, this leads to a larger exchange interface, thus increasing the amount of $\mathrm{HNO}_{3}$ diffusing to bulk ice in the total uptake. On the other hand, even if the ice covering the reactor's walls was smooth in the case of a frozen liquid film, the fast-freezing process would very likely lead to a highly polycrystalline structure, where grain boundaries may act as shortcuts for the diffusion, thus enhancing bulk uptake. Lastly, several authors (Hudson et al., 2002; Hynes et al., 2002) have pointed out that despite the careful attention to ensure that ice surface was in equilibrium with its vapour, part of the observed uptake could be ascribed to bulk incorporation of $\mathrm{HNO}_{3}$ with condensing water if the exposed ice was slightly growing because of slight supersaturation or due to the highly dynamic air-ice interface (Bolton and Pettersson, 2000).

More generally, the question of the adsorbed state, closely linked to the ionisation process and to the reversibility of the adsorption, can also explain the mismatch between the current parameterisation and measurements. In all the uptake experiments, it was observed that the total uptake splits between reversible and irreversible components, the former being only a minor part of the total. For instance, Ullerstam et al. (2005) reported that on average $20 \%$ of the initial uptake was desorbing. Should a part of this irreversible uptake already account for a strongly bound, bulk uptake, this could explain a major part of the overestimation of the modelled absorbed concentration. New investigations are needed to gain a clearer view of the partitioning between surface and bulk.

Finally, several other uncertainties can be invoked to explain the discrepancies. The saturated surface coverages reported in the various studies range over almost 1 order of magnitude, from $1.2 \times 10^{14}$ molec $\mathrm{cm}^{2}$ (Arora et al., 1999) to $1.0 \times 10^{15} \mathrm{molec}^{2}$ (Hynes et al., 2002). This uncertainty directly impacts the modelled surface coverage (Eq. 2). Secondly, most adsorption studies have used $\mathrm{HNO}_{3}$ partial pressure between 2 and 3 orders of magnitude higher than the one relevant at DC. Ullerstam et al. (2005) improved this by 
using partial pressures down to $\sim 9 \times 10^{-7} \mathrm{~Pa}$; however, this remains $\sim 25$ times higher than the lowest partial pressures measured in winter at DC $\left(\sim 3.5 \times 10^{-8} \mathrm{~Pa}\right)$. Using their parameterisation in DC conditions thus implies a great extrapolation. The lack of data for very low partial pressures is another potential uncertainty over the relevant type of adsorption isotherms, as the behaviour in the unsaturated region (i.e. at low partial pressure) provides more constraint over the best type of adsorption isotherms than that in (or near) the saturated region. This explains why several kinds of isotherms (dissociative (Hynes et al., 2002) or non-dissociative Langmuir isotherm (Ullerstam et al., 2005), Frenkel-Halsey-Hill isotherm (Hudson et al., 2002)) have been proposed but no clear consensus has been achieved.

In order to test these different explanations, experimental setups should systematically include measurements of the exposed area of ice and use partial pressures as low as possible. Processing the raw experimental data with the approach developed by Cox et al. (2005) seems a promising way to discriminate between surface and bulk uptake processes. Improvements in this approach could probably be achieved by using state-of-the-art parameterisation of the diffusion process.

Regarding the present study uncertainties, snow temperature, snow SSA, and $\mathrm{HNO}_{3}$ partial pressure are the three variables controlling the adsorbed surface coverage. $\mathrm{HNO}_{3}$ partial pressure, assumed to be equal to the total atmospheric nitrate (see Sect. 2.1.1), is thus the upper limit. However, as presented in the data description (see Sect. 2.1.1), this assumption likely leads to an overestimation not larger than $20 \%$ on average, which cannot explain the overestimation of the modelled concentration by a factor of 2.5-8.3. Conversely, the warm bias of modelled temperatures (see Sect. 2.2.1 and Supplement Sect. S1) leads to smaller modelled adsorption concentration, and the slightly reduced diurnal amplitude tends to reduce this other discrepancy between modelled and measured concentration. Lastly, the SSA was kept constant during the whole simulation, but a recent study by Libois et al. (2015) indicated that the SSA value adopted in our model is comparable to summer observations but 2-3 times lower than the winter SSA observations (see Sect. 2.2.2). At that time of the year, the modelled adsorbed concentration is already highly overestimated, thus accounting for a higher SSA would increase the discrepancy.

To conclude this section, several reasons were invoked to explain the overestimation of the modelled adsorbed concentration. In order to estimate the actual fraction of adsorbed nitrate over total snow nitrate, we make the rough hypothesis that the current adsorption parameterisation is flawed by a constant overestimation factor. Decreasing the modelled adsorbed concentration by a constant factor of $\sim 20$ so that its envelope never exceeds measured concentration leads to small adsorbed concentration during most of the year except in early spring, i.e. in the September-early November peak period (see Fig. 2b). In this situation, we estimate that ad- sorbed nitrate accounts for less than $13 \%$ of snow nitrate on yearly average (less than $9 \%$ when excluding the early September to early November period, and almost $30 \%$ during these 2 months). We thus decided thereafter to put aside the adsorption process, which should only lead to a minor error, except during spring. One way to test this hypothesis is to carry out hourly measurements of nitrate concentration in surface snow during spring. Owing to the strong temperature dependency of the adsorption isotherm, if adsorbed nitrate accounts for an important fraction of snow nitrate, then significant daily variations in snow nitrate concentration should be observed.

\section{Results and discussions for model configuration 2}

In this section, the model was run in configuration 2, based on the solid-state diffusion process (see Sect. 3.3). The results obtained with the three distinct $\mathrm{BC}$ parameterisations are successively presented and discussed hereafter.

\subsection{Thermodynamic equilibrium concentration (BC1)}

The first attempt to model nitrate concentration in the skin layer was done using solely the thermodynamic equilibrium concentration (see Sect. 3.3.2 and Eq. 8) to constrain the concentration of the external layer of the snow grain (BC1). The resulting concentration is plotted in Fig. 3 along with the measured concentration. The initial value of $\sim 500 \mathrm{ng} \mathrm{g}^{-1}$ and the sharp decrease at the beginning of the series (30 January 2009-7 February 2009) are due to the initialisation of the whole grain concentration to the closest measurement (point not shown, a few hours before the start of the simulation) and should not be interpreted. This spin-up duration shows that the time needed to re-equilibrate the snow grain concentration, roughly 2 weeks, compares well with the characteristic diffusion time (see Sect. 3.3).

From mid-April to late October, the modelled concentration is in reasonable agreement with the measured concentration, with some features appearing to be reproduced by the model (a slight, steady increase lasting from July to August, followed by a trough and then a second slight increase from September to mid-October). During this winter period, the modelled concentration appears to be often slightly lower than the measurements; this point will be further discussed in the sensitivity study presented in Sect. 5.4. The modelled concentration also features smoother variations than the measurements, which can be mainly explained by the coarse time resolution of $\mathrm{HNO}_{3}$ partial pressure used as input, of roughly one week (see Sect. 2.1.1 and Fig. 1a). The good consistency between modelled and measured concentrations during winter months is an important result, as this indicates that winter concentration of nitrate in surface snow is mainly driven by the thermodynamic equilibrium solubility, coupled to solidstate diffusion. 


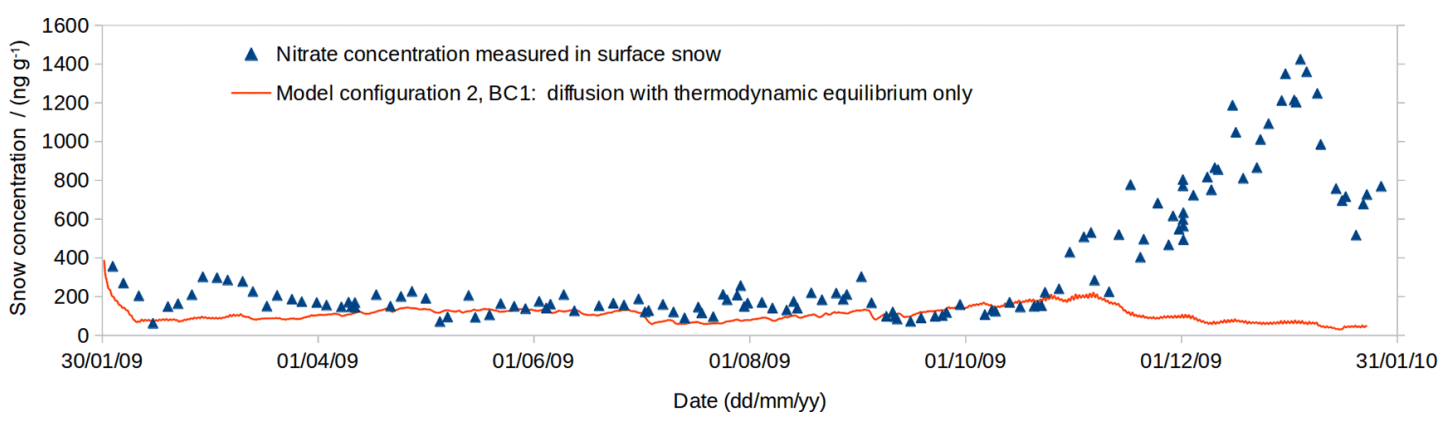

Figure 3. Nitrate concentration measured in the skin layer (blue triangles) and modelled using only thermodynamic solubility to constrain the air-snow partitioning (model configuration 2, BC1; orange line). The output time step is $4 \mathrm{~h}$.

On the other hand, this first modelling attempt clearly fails to reproduce the summer peak of nitrate concentration in snow, with values in the $50-200 \mathrm{ng} \mathrm{g}^{-1}$ range from November to early April, while measured concentration peaks above $1400 \mathrm{ng} \mathrm{g}^{-1}$. These results also show that summer concentration of nitrate in surface snow is highly enriched compared to what is expected from the thermodynamic equilibrium. These results demonstrate that another uptake process, driven by kinetics rather than thermodynamics, is needed to explain such high summer concentration.

\subsection{Diagnostic co-condensation parameterisation (BC2)}

The BC2 includes the kinetic co-condensation process, through the empirical diagnostic parameterisation presented in Sect. 3.3.3.

We adjusted the three coefficients in Eq. (11) in order to minimise the RMSE between modelled and measured snow nitrate concentration. The optimal result, plotted in Fig. 5, was obtained with $X_{\mathrm{HNO}_{3}}=X_{\mathrm{HNO}_{3}}^{0}+\alpha \times P_{\mathrm{HNO}_{3}}^{0.43} \times P_{\mathrm{H}_{2} \mathrm{O}}^{1.27}$. The $\alpha$ parameter value was adjusted so that the amplitude of the modelled summer peak fit the data, but it has no physical signification. However, the most relevant point to note is that the modelled peak is well in phase with the measurements (as a main difference with the adsorption), and both time series display similar features. Furthermore, it is worth noting that including the co-condensation has not degraded the winter prediction. Indeed, because of the very low winter temperature at DC, and given the exponential dependency of water vapour pressure over temperature, the co-condensation term becomes almost negligible (Town et al., 2008).

The optimum exponent for $\mathrm{HNO}_{3}$ partial pressure is 0.43 , which exactly corresponds to the exponent for $\mathrm{HNO}_{3}$ partial pressure of thermodynamic equilibrium concentration (in Eq. $8,1 / 2.3 \simeq 0.43$ ). Even if that needs to be confirmed by further investigations, this result tends to confirm the hypothesis formulated by Ullerstam and Abbatt (2005) that thermodynamic partitioning plays a role in the co-condensation process (see Sect. 3.3.3).
Because of the correct timing and shape of the modelled peak of nitrate, these results suggest that the co-condensation process is responsible for the out-of-equilibrium, high concentration of nitrate in the skin layer in summer. Among the two available laws giving $X_{\text {kin }}$ (i.e. the concentration of the growing phase; see Sect. 3.3.3, Eq. 9 or 10), the empirical one, whose dependency over the $\mathrm{HNO}_{3}$ partial pressure is the closest to 0.43 , seems the more suited to reproduce the observations.

\subsection{Prognostic co-condensation parameterisation (BC3)}

The last part of this work aimed at refining the parameterisation for the co-condensation process, using physically based variables. The prognostic parameterisation developed hereafter is referred to as BC3. For the sake of simplicity, and because the growth of snow grain is very slow compared to the recycling of vapour as suggested by Pinzer et al. (2012), a constant radius $(R)$ is assumed. However, the growth law defined in Eq. (12) is used in order to evaluate the equivalent radius increase $\Delta R$ resulting from the cocondensation process during the model time step $\Delta t$ (Eq. 14). Finally, the concentration resulting from concomitant thermodynamic process (diffusion equilibration) and kinetic process (co-condensation process) is calculated using the theoretical Eq. (15) at depth $\Delta R$, which is at the surface of the modelled snow grain whose radius is supposed to be constant.

The radius growth rate $\Delta R / \Delta t$ as derived from Eq. (14) is presented in Fig. 4. It spans roughly 3 orders of magnitude over the year, from about $10^{-12} \mathrm{~m} \mathrm{~s}^{-1}$ in winter to $\sim 8 \times 10^{-10} \mathrm{~m} \mathrm{~s}^{-1}$ in summer. The explanation of this behaviour is twofold. First, the diurnal temperature cycle has a larger amplitude in summer, which enhances the temperature gradient close to the surface. Second, the vapour pressure over ice increases exponentially with temperature. As a consequence, with a given value of the temperature gradient, the gradient of water vapour concentration used in Eq. (12) is larger if temperatures are higher. This also explains the diurnal variation in the grain radius growth. The most striking 


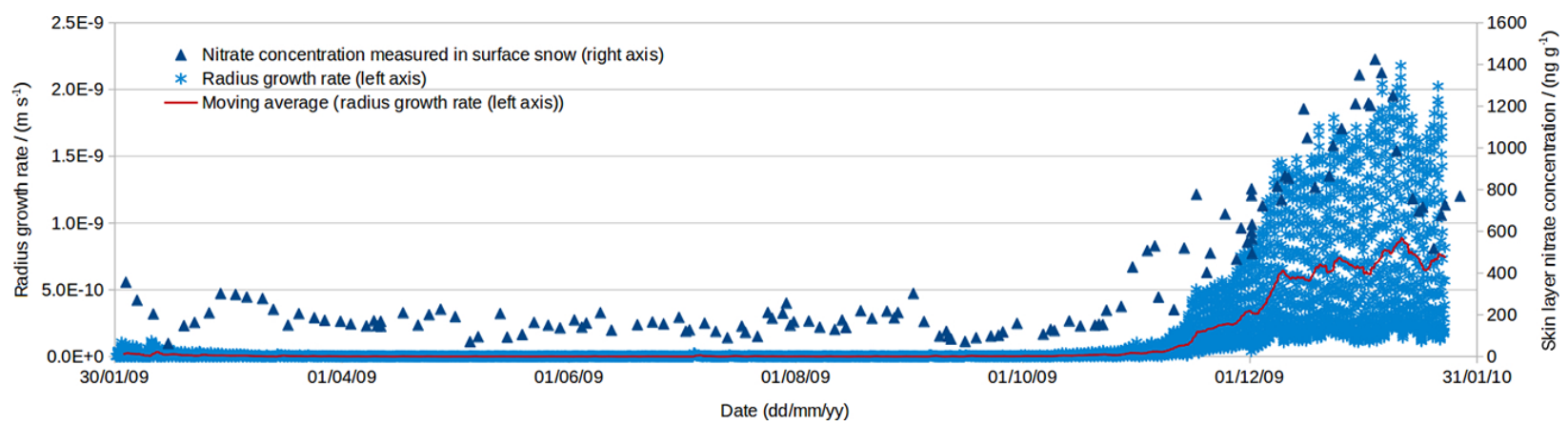

Figure 4. Radius growth rate calculated according to Eq. (14). Hourly data (blue asterisks) is plotted along with a moving average (red line). Nitrate concentration in the skin layer (blue triangles, right axis) is plotted for a comparison of both yearly patterns.

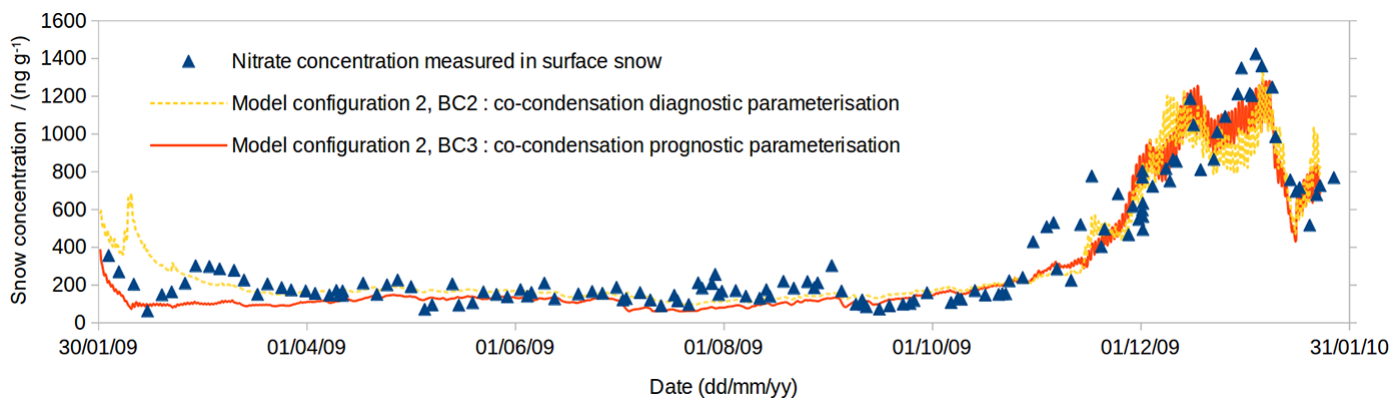

Figure 5. Nitrate concentration measured in the skin layer (blue triangles) and modelled in configuration 2 using two distinct parameterisations of the co-condensation process: diagnostic parameterisation ( $\mathrm{BC} 2$, dashed yellow line) and physically based prognostic parameterisation (BC3, solid red line).

feature of the radius growth rate is that it peaks during the same period of the year that the peak of nitrate concentration in the skin layer. The yearly pattern of the radius growth rate predicted by our model is also consistent with independent studies focused on snow physical properties (Picard et al., 2012; Libois et al., 2015). This comes as additional evidence that snow metamorphism and co-condensation have a major influence on the snow chemical concentration.

The resulting modelled nitrate concentration in surface snow is presented in Fig. 5. In Table 1, a summary of the model runs, along with their RMSE, is presented. Simulation results are similar to those obtained with the $\mathrm{BC} 2$ parameterisation, but with a slightly improved RMSE. A diurnal variation in the modelled concentration is observed, as a consequence of the diurnal variation in the radius growth rate. However, the diurnal variation in the concentration is much smoother because solid-state diffusion in the whole snow grain softens the large diurnal variations in the outermost layer of the snow grain. The relative diurnal variation in the concentration is always smaller than $20 \%$ and thus cannot be distinguished from the measurements uncertainties due to spatial heterogeneity. In this physically based parameterisation, a slight dependency of the results to the model time step arises. This is explained by the radius increase $\Delta R$ which depends on the cubic root of the time (Eq. 14), and which is divided by the square root of the time in Eq. (15). To compensate for this unphysical dependency, either the time step of the model needs to be adjusted for optimum results or a correction factor can be used in order to keep the time step unchanged, with a value well suited regarding the diffusion process. The exact reason of this dependency over the time step is complex to establish, but it can very likely be ascribed to the hypothesised geometry of the snow grain (a sphere) and of the condensed phase (a layer). Improving this point necessitates determination of the relationship between mean thickness of the co-condensed layer as a function of time, which is left to further work.

In Fig. 5, the modelled concentration shows a poorer fit with the measured concentration during spring, just before the observed peak of snow nitrate. This is confirmed by a lower correlation from September to November (Table S1), which corresponds to the period where the modelled adsorption peaks (see Fig. 2). This is another indication that adsorbed nitrate may account for a noticeable part of surface snow nitrate in early spring.

As stated in the introduction, the photolysis has not been included in this study since the dramatic increase in summer nitrate concentration in the skin layer demonstrate that uptake processes overtake loss processes in this specific layer. In order to refine this comparison regarding the budget of ni- 
Table 1. Summary of the main simulations with their description, along with the RMSE value to evaluate the discrepancy between modelled and measured values. If relevant, the numbering of the figure where results are plotted is indicated.

\begin{tabular}{|c|c|c|}
\hline Simulation description & $\mathrm{RMSE} \mathrm{ng} \mathrm{g}^{-1}$ & Fig. \\
\hline Configuration 1: adsorption & 551 & 2 \\
\hline Configuration 2: diffusion with thermodynamic solubility only (BC1) & 437 & 3 \\
\hline Configuration 2: diffusion with diagnostic parameterisation of the co-condensation (BC2) & 124 & 5 \\
\hline Configuration 2: diffusion with prognostic parameterisation of the co-condensation (BC3) & 116 & 5 \\
\hline Sensitivity study, solubility increased by $39 \%$ & 110 & \\
\hline Sensitivity study, diffusion coefficient decreased by $72 \%$ & 100 & \\
\hline Sensitivity study, solubility increased by $39 \%$ and diffusion coefficient decreased by $64 \%$ & 96 & \\
\hline $\begin{array}{l}\text { Sensitivity study, solubility increased by } 39 \% \text { and SSA value decreased to } 23 \mathrm{~m}^{2} \mathrm{~kg}^{-1} \\
\text { (initial value }=38 \mathrm{~m}^{2} \mathrm{~kg}^{-1} \text { ) }\end{array}$ & 96 & \\
\hline
\end{tabular}

trate in the skin layer, an estimation of the uptake and loss fluxes is presented here. Both calculations are based on the following assumptions: a skin layer thickness of $3 \mathrm{~mm}$, with a snow density of $0.3 \mathrm{~kg} \mathrm{~m}^{-3}$. The fluxes are calculated for an area of $1 \mathrm{~cm}^{2}$.

The photolysis flux is calculated for a single nitrate concentration of $1200 \mathrm{ng} \mathrm{g}^{-1}$, which results in $9.7 \times$ $10^{14}$ molecules in the $1 \mathrm{~cm}^{2} \times 3 \mathrm{~mm}$ volume. France et al. (2011) reported a photolysis rate for nitrate of about $1 \times$ $10^{-7} \mathrm{~s}^{-1}$ in Dome $\mathrm{C}$ surface snow, for a solar zenith angle (SZA) of $52^{\circ}$, which is the maximum solar elevation at Dome C. The resulting photolytic loss flux is $9.7 \times$ $10^{7}$ molecules $\mathrm{cm}^{-2} \mathrm{~s}^{-1}$.

The uptake flux resulting from the co-condensation process is calculated by assuming that the $1 \mathrm{~cm}^{2} \times 3 \mathrm{~mm}$ volume is filled with ice spheres of radius $R=85 \mu \mathrm{m}$ (see Sect. 2.2.2) up to the prescribed density. This results in $\sim 37200$ spheres. In the theoretical study by Dominé and Thibert (1996), the average concentration in the condensed layer immediately before another layer condenses and isolates the previous one is given by the integral of Eq. (15) over the condensed thickness $\Delta R$ :

$X_{\text {average }}=X_{\text {kin }}+\left(\frac{X_{\text {eq }}-X_{\text {kin }}}{\Delta R}\right) \int_{0}^{\Delta R} \operatorname{erfc}\left(\frac{x}{2 \sqrt{D t}}\right) \mathrm{d} x$.

Using the same input data as in the model, and assuming that this average concentration multiplied by the condensed volume corresponds to the quantity of nitrate actually taken up by the snow, we calculate an average uptake flux of $5.4 \times 10^{9}$ molecules $\mathrm{cm}^{-2} \mathrm{~s}^{-1}$ over the December 2009 to January 2010 period. The minimum and maximum values are $1.6 \times 10^{8}$ and $2.7 \times 10^{10}$ molecules $\mathrm{cm}^{-2} \mathrm{~s}^{-1}$, respectively. Strong negative gradients have been reported above snow surface (see, for instance, the measurements by Dibb et al., 2004 (their Fig. 3) at South Pole), but only one $\mathrm{HNO}_{3}$ flux measurement was found in the literature (Beine et al., 2003). This work was carried out in the Arctic, and due to the numerous differences between both locations (type of snowpack, temperature, and temperature gradient), a close comparison is not possible. Beine et al. (2003) reported an average value of $1.2 \times 10^{9}$ molecules $\mathrm{cm}^{-2} \mathrm{~s}^{-1}$ (interquartile range: $6.3 \times 10^{8}-2.4 \times 10^{9}$ molecules $\mathrm{cm}^{-2} \mathrm{~s}^{-1}$ ). The uptake flux ascribed to the co-condensation has the same order of magnitude as this measured flux, which seems promising. However, $\mathrm{HNO}_{3}$ flux measurements should be carried out in Dome $\mathrm{C}$ in order to allow a realistic comparison.

As a conclusion, the uptake flux due to the cocondensation appears to be $\sim 56$ times larger, on average, than the photolysis loss flux calculated for the highest solar elevation conditions. This confirms that photolysis loss can be neglected when studying the nitrate concentration in the skin layer. Given the numerous assumptions made in the model, the overall reproduction of the measurements by the parameterisation including co-condensation appears satisfactory.

\subsection{Sensitivity study}

In order to further investigate the modelling uncertainties, the sensitivity of the model to the thermodynamic equilibrium concentration, diffusion coefficient and SSA value is evaluated. A synthesis of RMSE values of the sensitivity runs is presented in Table 1.

As shown in Sect. 5.1, winter modelled concentration underestimates the measurements, which could be explained by an underestimated thermodynamic equilibrium solubility (Eq. 8). The best fit with the data is obtained for an increase of $39 \%$ (see Table 1). This optimum increase is almost twice as much as the uncertainty reported by Thibert and Dominé (1998, 20\%); however, we applied the solubility parameterisation at much lower temperature than in their study, which could explain the results.

A few measurements of the ratio of $\mathrm{HNO}_{3}$ over atmospheric nitrate presented in Sect. 2.1.1 suggest that $\mathrm{HNO}_{3}$ might account for roughly $70-90 \%$ of atmospheric nitrate. Taking this ratio into account would reduce the $\mathrm{HNO}_{3}$ partial pressure used as input in the model but might be counterbalanced by a further increase in the thermodynamic solubility. New studies are needed to confirm the speciation of 
atmospheric nitrate and its seasonal variation. On the other hand, the current underestimation of the modelled concentration during winter can also be partly ascribed to a small adsorbed fraction amongst the total snow nitrate.

Secondly, using a diffusion coefficient lower than that suggested by Thibert and Dominé (1998, their Eq. 7) generally improves the simulation performance. Using BC3 simulation as a reference, decreasing the diffusion coefficient by $72 \%$ leads to the best reproduction of the results (see Table 1 ). When the solubility value increased by $39 \%$ is used, the diffusion coefficient is decreased by $64 \%$. Thibert and Dominé (1998) reported a $60 \%$ uncertainty for the diffusion coefficient and indicated that their parameterisation likely represents the upper bounds, which compares well with the present sensitivity analysis.

However, another explanation is possible: a decrease in SSA linked to an increased radius (Eq. 1) has a similar effect to a decrease in the diffusion coefficient. Decreasing SSA to $23 \mathrm{~m}^{2} \mathrm{~kg}^{-1}$ leads to almost the same result as reducing the diffusion coefficient by $64 \%$ (see Table 1 ). In the current version of the model, the radius of the snow grain is kept constant over time as a simple hypothesis, but it has been shown by Picard et al. $(2012,2016)$ and Libois et al. (2015) that snow grain size features a sharp increase at DC during December and January, when the modelled water vapour fluxes driving the co-condensation process are highest. It is remarkable that the optimum value of $23 \mathrm{~m}^{2} \mathrm{~kg}^{-1}$ is in very good agreement with that observed in summer (Libois et al., 2015, their Fig. 1). Future development of the current work should consider grain size change to distinguish between these two alternative hypotheses.

\section{Conclusions}

In this study we investigated the role of three processes that intervene in air-snow exchange of nitrate at DC. It revealed that the co-condensation of nitrate along with the condensation of water vapour flux driven by thermal gradient metamorphism is a major process that is absolutely required to explain the summer peak of nitrate measured in surface snow.

This study further reveals that the current state-of-theart parameterisation for $\mathrm{HNO}_{3}$ adsorption on snow leads to modelled concentration which differs from the observations and cannot be used without major changes. We propose the hypothesis that adsorption measurements of $\mathrm{HNO}_{3}$ on ice attributed most, if not all, of the uptake to the only adsorption process, while a noticeable part of this uptake should in fact be ascribed to bulk, irreversible incorporation. In order to make a clearer distinction between surface and bulk nitrate on the ice, new laboratory investigations should be conducted along with theoretical studies in order to improve the current understanding of the binding process occurring on the ice surface and its kinetics. However, studies aiming at the determination of equilibrium solubility and diffusion coefficient of nitrate in the ice take advantage of "integrative" measurements, in the sense that these two properties are deduced from macroscopic concentration profiles in the ice without needing a further hypothesis or insight into the actual microscopic processes occurring at the air-ice interface (binding, ionisation, solvation). This different approach probably explains why, despite being much less numerous, these studies provided robust parameterisations. Assuming that the adsorption parameterisation is overestimated by a constant factor which would leave the yearly pattern unchanged, the maximum featured by the modelled adsorbed concentration in September and October suggests that adsorbed nitrate might account for roughly $30 \%$ of snow nitrate during these 2 months. As for the rest of the year, and based on the same hypothesis, adsorbed nitrate should account for less than $10 \%$ of snow nitrate.

Thus, by ignoring the adsorption process, and focusing solely on the solid-state diffusion inside a spherical snow grain, we developed a physically based parameterisation for the concentration at the surface of this grain, used as the boundary condition of the diffusion equation. This parameterisation combines both thermodynamic and kinetic (cocondensation) uptake processes. Without needing any further parameter adjustment, the implementation of this newly developed parameterisation allowed a satisfactory reproduction of the 1-year-long dataset of nitrate concentration in DC surface snow. Given the similar general features of the measurements of atmospheric and snow nitrate in other Antarctic sites such as South Pole or even Halley, it seems likely that the modelling framework that we developed applies at least to the Antarctic Plateau.

Even if some improvements still need to be done, especially regarding a more realistic geometry of the cocondensed phase, the developed parameterisation and the overall modelling scheme can already be implemented as a foundation piece in one-dimensional (1-D) snowatmosphere models. Some new insights into nitrogen recycling inside the snowpack could ensue from such vertical, 1D modelling. In this study focused on skin layer snow, nitrate photolysis inside the snow grain has not been implemented since nitrate loss is much weaker than uptake for this specific layer, as inferred by the dramatic increase in nitrate concentration during summer and further confirmed by loss and uptake fluxes comparison. This intense uptake in the skin layer is driven by the strong temperature gradients in the upper centimetres of the snowpack. This is not necessarily true for the whole snowpack, and photolysis should be included in a 1-D snow chemistry model. For that purpose, the description of a snow grain as a layered medium will enable the use of different quantum yields, after some studies suggesting that it spans more than 2 orders of magnitude depending on the availability of nitrate inside the ice matrix (Zhu et al., 2010; Meusinger et al., 2014).

Ultimately, this work shows that snow physics and snow chemistry are tightly coupled, and especially that snow meta- 
morphism resulting mainly from temperature gradients does not affect solely the physical properties of the snow but also its chemical composition. It is also worth noting that physical exchange processes on their own appear to explain a major part of the observed changes in surface snow nitrate at DC. Thus, it seems highly necessary that any field campaign mainly dedicated to snow chemistry also devotes efforts to accurate measurements of snow physical properties.

\section{Code availability}

The model code is available upon request from the corresponding author.

\section{The Supplement related to this article is available online at doi:10.5194/acp-16-12531-2016-supplement.}

Author contributions. J. Savarino initiated this study on the basis of field data collected in the framework of NITE DC programme. J. Bock developed the co-condensation parameterisation, developed the model code, and performed the simulations. G. Picard carried out the surface energy budget and thermal diffusion simulations to get the snow temperature. All co-authors contributed to the development of the modelling framework. J. Bock prepared the manuscript with contributions from all co-authors.

Acknowledgements. We wish to thank Frédéric Flin for helpful discussions about water vapour exchange and its parameterisation inside the snowpack. We are grateful to Emmanuel Witrant and David Stevens for helpful discussions about the implementation of various boundary conditions of the diffusion equation. We thank James France, Max Thomas, and Sarah Voke for proofreading the final manuscript. J. Bock is grateful to Christian George for co-supervising his PhD. We thank the reviewers and the co-editor for their help in improving our manuscript.

Edited by: V. F. McNeill

Reviewed by: two anonymous referees

\section{References}

Abbatt, J. P. D.: Interaction of $\mathrm{HNO}_{3}$ with water-ice surfaces at temperatures of the free troposphere, Geophys. Res. Lett., 24, 1479-1482, doi:10.1029/97GL01403, 1997.

Abbatt, J. P. D.: Interactions of atmospheric trace gases with ice surfaces: adsorption and reaction, Chem. Rev., 103, 4783-4800, doi:10.1021/cr0206418, 2003.

Abbatt, J. P. D., Bartels-Rausch, T., Ullerstam, M., and Ye, T. J.: Uptake of acetone, ethanol and benzene to snow and ice: effects of surface area and temperature, Environ. Res. Lett., 3, 045008, doi:10.1088/1748-9326/3/4/045008, 2008.
Arimoto, R., Zeng, T., Davis, D., Wang, Y., Khaing, H., Nesbit, C., and Huey, G.: Concentrations and sources of aerosol ions and trace elements during ANTCI-2003, Atmos. Environ., 42, 28642876, doi:10.1016/j.atmosenv.2007.05.054, 2008.

Arora, O. P., Cziczo, D. J., Morgan, A. M., Abbatt, J. P. D., and Niedziela, R. F.: Uptake of nitric acid by sub-micronsized ice particles, Geophys. Res. Lett., 26, 3621-3624, doi:10.1029/1999GL010881, 1999.

Bales, R. C., Losleben, M. V., McConnell, J. R., Fuhrer, K., and Neftel, A.: $\mathrm{H}_{2} \mathrm{O}_{2}$ in snow, air and open pore space in firn at Summit, Greenland, Geophys. Res. Lett., 22, 1261-1264, doi:10.1029/95GL01110, 1995.

Barret, M., Dominé, F., Houdier, S., Gallet, J.-C., Weibring, P., Walega, J., Fried, A., and Richter, D.: Formaldehyde in the Alaskan Arctic snowpack: partitioning and physical processes involved in air-snow exchanges, J. Geophys. Res., 116, D00R03, doi:10.1029/2011JD016038, 2011a.

Barret, M., Houdier, S., and Dominé, F.: Thermodynamics of the formaldehyde-water and formaldehyde-ice systems for atmospheric applications, J. Phys. Chem. A, 115, 307-317, doi:10.1021/jp108907u, 2011b.

Beine, H., Dominé, F., Simpson, W., Honrath, R., Sparapani, R., Zhou, X., and King, M.: Snow-pile and chamber experiments during the Polar Sunrise Experiment "Alert 2000": exploration of nitrogen chemistry, Atmos. Environ., 36, 2707-2719, doi:10.1016/S1352-2310(02)00120-6, 2002.

Beine, H. J., Dominé, F., Ianniello, A., Nardino, M., Allegrini, I., Teinilä, K., and Hillamo, R.: Fluxes of nitrates between snow surfaces and the atmosphere in the European high Arctic, Atmos. Chem. Phys., 3, 335-346, doi:10.5194/acp-3-335-2003, 2003.

Berhanu, T. A., Meusinger, C., Erbland, J., Jost, R., Bhattacharya, S. K., Johnson, M. S., and Savarino, J.: Laboratory study of nitrate photolysis in Antarctic snow. II. Isotopic effects and wavelength dependence, J. Chem. Phys., 140, 244306, doi:10.1063/1.4882899, 2014.

Bianco, R., Wang, S., and Hynes, J. T.: Theoretical study of the dissociation of nitric acid at a model aqueous surface, J. Phys. Chem. A, 111, 11033-11042, doi:10.1021/jp075054a, 2007.

Bianco, R., Wang, S., and Hynes, J. T.: Infrared signatures of $\mathrm{HNO}_{3}$ and $\mathrm{NO}_{3}^{-}$at a model aqueous surface. A theoretical study, J. Phys. Chem. A, 112, 9467-9476, doi:10.1021/jp802563g, 2008.

Bock, J. and Jacobi, H.-W.: Development of a mechanism for nitrate photochemistry in snow, J. Phys. Chem. A, 114, 1790-1796, doi:10.1021/jp909205e, 2010.

Bolton, K. and Pettersson, J. B. C.: A molecular dynamics study of the long-time ice Ih surface dynamics, J. Phys. Chem. B, 104, 1590-1595, doi:10.1021/jp9934883, 2000.

Boxe, C. S. and Saiz-Lopez, A.: Multiphase modeling of nitrate photochemistry in the quasi-liquid layer (QLL): implications for $\mathrm{NO}_{x}$ release from the Arctic and coastal Antarctic snowpack, Atmos. Chem. Phys., 8, 4855-4864, doi:10.5194/acp-8-4855-2008, 2008.

Brandt, R. E. and Warren, S. G.: Solar-heating rates and temperature profiles in Antarctic snow and ice, J. Glaciol., 39, 99-110, doi:10.3198/1993JoG39-131-99-110, 1993.

Brun, E., Six, D., Picard, G., Vionnet, V., Arnaud, L., Bazile, E., Boone, A., Bouchard, A., Genthon, C., Guidard, V., Le Moigne, P., Rabier, F., and Seity, Y.: Snow/atmosphere coupled sim- 
ulation at Dome C, Antarctica, J. Glaciol., 57, 721-736, doi:10.3189/002214311797409794, 2011.

Buch, V., Sadlej, J., Aytemiz-Uras, N., and Devlin, J. P.: Solvation and ionization stages of $\mathrm{HCl}$ on ice nanocrystals, J. Phys. Chem. A, 106, 9374-9389, doi:10.1021/jp021539h, 2002.

Calonne, N., Geindreau, C., and Flin, F.: Macroscopic modeling for heat and water vapor transfer in dry snow by homogenization, J. Phys. Chem. B, 118, 13393-13403, doi:10.1021/jp5052535, 2014.

Champollion, N., Picard, G., Arnaud, L., Lefebvre, E., and Fily, M.: Hoar crystal development and disappearance at Dome C, Antarctica: observation by near-infrared photography and passive microwave satellite, The Cryosphere, 7, 1247-1262, doi:10.5194/tc-7-1247-2013, 2013.

Chu, L. and Anastasio, C.: Quantum yields of hydroxyl radical and nitrogen dioxide from the photolysis of nitrate on ice, J. Phys. Chem. A, 107, 9594-9602, doi:10.1021/jp0349132, 2003.

Chu, L. and Anastasio, C.: Temperature and wavelength dependence of nitrite photolysis in frozen and aqueous solutions, Environ. Sci. Technol., 41, 3626-3632, doi:10.1021/es062731q, 2007.

Colbeck, S.: Snow-crystal growth with varying surface temperatures and radiation penetration, J. Glaciol., 35, 23-29, doi:10.3189/002214389793701536, 1989.

Conklin, M. H., Sigg, A., Neftel, A., and Bales, R. C.: Atmospheresnow transfer function for $\mathrm{H}_{2} \mathrm{O}_{2}$ : microphysical considerations, J. Geophys. Res., 98, 18367-18376, doi:10.1029/93JD01194, 1993.

Cotter, E. S. N., Jones, A. E., Wolff, E. W., and Bauguitte, S. J.B.: What controls photochemical $\mathrm{NO}$ and $\mathrm{NO}_{2}$ production from Antarctic snow? Laboratory investigation assessing the wavelength and temperature dependence, J. Geophys. Res., 108, 4147, doi:10.1029/2002JD002602, 2003.

Cox, R. A., Fernandez, M. A., Symington, A., Ullerstam, M., and Abbatt, J. P. D.: A kinetic model for uptake of $\mathrm{HNO}_{3}$ and $\mathrm{HCl}$ on ice in a coated wall flow system, Phys. Chem. Chem. Phys., 7, 3434-3442, doi:10.1039/b506683b, 2005.

Crowley, J. N., Ammann, M., Cox, R. A., Hynes, R. G., Jenkin, M. E., Mellouki, A., Rossi, M. J., Troe, J., and Wallington, T. J.: Evaluated kinetic and photochemical data for atmospheric chemistry: Volume V - heterogeneous reactions on solid substrates, Atmos. Chem. Phys., 10, 9059-9223, doi:10.5194/acp-10-90592010, 2010.

Davis, D., Eisele, F., Chen, G., Crawford, J., Huey, G., Tanner, D., Slusher, D., Mauldin, L., Oncley, S., Lenschow, D., Semmer, S., Shetter, R., Lefer, B., Arimoto, R., Hogan, A., Grube, P., Lazzara, M., Bandy, A., Thornton, D., Berresheim, H., Bingemer, H., Hutterli, M., McConnell, J., Bales, R., Dibb, J., Buhr, M., Park, J., McMurry, P., Swanson, A., Meinardi, S., and Blake, D.: An overview of ISCAT 2000, Atmos. Environ., 38, 5363-5373, doi:10.1016/j.atmosenv.2004.05.037, 2004.

Davis, D., Seelig, J., Huey, G., Crawford, J., Chen, G., Wang, Y., Buhr, M., Helmig, D., Neff, W., and Blake, D.: A reassessment of Antarctic plateau reactive nitrogen based on ANTCI 2003 airborne and ground based measurements, Atmos. Environ., 42, 2831-2848, doi:10.1016/j.atmosenv.2007.07.039, 2008.

Dibb, J. E., Talbot, R. W., Munger, J. W., Jacob, D. J., and Fan, S.-M.: Air-snow exchange of $\mathrm{HNO}_{3}$ and $\mathrm{NO}_{y}$ at Summit, Greenland, J. Geophys. Res., 103, 3475-3486, doi:10.1029/97JD03132, 1998.

Dibb, J. E., Arsenault, M., Peterson, M. C., and Honrath, R. E.: Fast nitrogen oxide photochemistry in Summit, Greenland snow, Atmos. Environ., 36, 2501-2511, doi:10.1016/S13522310(02)00130-9, 2002.

Dibb, J. E., Gregory Huey, L., Slusher, D. L., and Tanner, D. J.: Soluble reactive nitrogen oxides at South Pole during ISCAT 2000, Atmos. Environ., 38, 5399-5409, doi:10.1016/j.atmosenv.2003.01.001, 2004.

Dominé, F. and Rauzy, C.: Influence of the ice growth rate on the incorporation of gaseous $\mathrm{HCl}$, Atmos. Chem. Phys., 4, 2513-2519, doi:10.5194/acp-4-2513-2004, 2004.

Dominé, F. and Thibert, E.: Relationship between atmospheric composition and snow composition for $\mathrm{HCl}$ and $\mathrm{HNO}_{3}$, in: Proceedings of a Boulder Symposium, IAHS Publ. no. 228, pp. 3-10, edited by: Tonnessen, K. A., Williams, M. W., and Tranter, M., 12-13 July 1995, Boulder, Colorado, USA, 1995.

Dominé, F. and Thibert, E.: Mechanism of incorporation of trace gases in ice grown from the gas phase, Geophys. Res. Lett., 23 3627-3630, doi:10.1029/96GL03290, 1996.

Dominé, F., Thibert, E., Van Landeghem, F., Silvente, E., and Wagnon, P.: Diffusion and solubility of $\mathrm{HCl}$ in ice: preliminary results, Geophys. Res. Lett., 21, 601-604, doi:10.1029/94GL00512, 1994.

Dominé, F., Thibert, E., Silvente, E., Legrand, M., and Jaffrezo, J.-L.: Determining past atmospheric $\mathrm{HCl}$ mixing ratios from ice core analyses, J. Atmos. Chem., 21, 165-186, doi:10.1007/BF00696579, 1995.

Dominé, F., Albert, M., Huthwelker, T., Jacobi, H.-W., Kokhanovsky, A. A., Lehning, M., Picard, G., and Simpson, W. R.: Snow physics as relevant to snow photochemistry, Atmos. Chem. Phys., 8, 171-208, doi:10.5194/acp-8-171-2008, 2008.

Dominé, F., Bock, J., Voisin, D., and Donaldson, D. J.: Can we model snow photochemistry? Problems with the current approaches, J. Phys. Chem. A, 117, 4733-4749, doi:10.1021/jp3123314, 2013.

Dubowski, Y., Colussi, A. J., and Hoffmann, M. R.: Nitrogen dioxide release in the $302 \mathrm{~nm}$ band photolysis of spray-frozen aqueous nitrate solutions. Atmospheric implications, J. Phys. Chem. A, 105, 4928-4932, doi:10.1021/jp0042009, 2001.

Dubowski, Y., Colussi, A. J., Boxe, C., and Hoffmann, M. R.: Monotonic increase of nitrite yields in the photolysis of nitrate in ice and water between 238 and 294 K, J. Phys. Chem. A, 106, 6967-6971, doi:10.1021/jp0142942, 2002.

Ebner, P. P., Andreoli, C., Schneebeli, M., and Steinfeld, A.: Tomography-based characterization of ice-air interface dynamics of temperature gradient snow metamorphism under advective conditions, J. Geophys. Res.-Earth, 120, 2437-2451, doi:10.1002/2015JF003648, 2015.

Eisele, F., Davis, D., Helmig, D., Oltmans, S., Neff, W., Huey, G., Tanner, D., Chen, G., Crawford, J., and Arimoto, R.: Antarctic Tropospheric Chemistry Investigation (ANTCI) 2003 overview, Atmos. Environ., 42, 2749-2761, doi:10.1016/j.atmosenv.2007.04.013, 2008.

Erbland, J., Vicars, W. C., Savarino, J., Morin, S., Frey, M. M., Frosini, D., Vince, E., and Martins, J. M. F.: Air-snow transfer of nitrate on the East Antarctic Plateau - Part 1: Isotopic evi- 
dence for a photolytically driven dynamic equilibrium in summer, Atmos. Chem. Phys., 13, 6403-6419, doi:10.5194/acp-136403-2013, 2013.

Erbland, J., Savarino, J., Morin, S., France, J. L., Frey, M. M., and King, M. D.: Air-snow transfer of nitrate on the East Antarctic Plateau - Part 2: An isotopic model for the interpretation of deep ice-core records, Atmos. Chem. Phys., 15, 12079-12113, doi:10.5194/acp-15-12079-2015, 2015.

Finlayson-Pitts, B. J. and Pitts, J. N.: Chemistry of the upper and lower atmosphere: theory, experiments, and applications, Academic Press, San Diego, USA, 2000.

Flanner, M. G. and Zender, C. S.: Linking snowpack microphysics and albedo evolution, J. Geophys. Res., 111, D12208, doi:10.1029/2005JD006834, 2006.

Flin, F. and Brzoska, J.-B.: The temperature-gradient metamorphism of snow: vapour diffusion model and application to tomographic images, Ann. Glaciol., 49, 17-21, doi:10.3189/172756408787814834, 2008.

Flin, F., Brzoska, J.-B., Lesaffre, B., Coléou, C., and Pieritz, R. A.: Full three-dimensional modelling of curvature-dependent snow metamorphism: first results and comparison with experimental tomographic data, J. Phys. D Appl. Phys., 36, A49-A54, doi:10.1088/0022-3727/36/10A/310, 2003.

France, J. L., King, M. D., Frey, M. M., Erbland, J., Picard, G., Preunkert, S., MacArthur, A., and Savarino, J.: Snow optical properties at Dome C (Concordia), Antarctica; implications for snow emissions and snow chemistry of reactive nitrogen, Atmos. Chem. Phys., 11, 9787-9801, doi:10.5194/acp-11-97872011, 2011.

Fréville, H., Brun, E., Picard, G., Tatarinova, N., Arnaud, L., Lanconelli, C., Reijmer, C., and van den Broeke, M.: Using MODIS land surface temperatures and the Crocus snow model to understand the warm bias of ERA-Interim reanalyses at the surface in Antarctica, The Cryosphere, 8, 1361-1373, doi:10.5194/tc-81361-2014, 2014.

Frey, M. M., Savarino, J., Morin, S., Erbland, J., and Martins, J. M. F.: Photolysis imprint in the nitrate stable isotope signal in snow and atmosphere of East Antarctica and implications for reactive nitrogen cycling, Atmos. Chem. Phys., 9, 8681-8696, doi:10.5194/acp-9-8681-2009, 2009.

Gallet, J.-C., Dominé, F., Arnaud, L., Picard, G., and Savarino, J.: Vertical profile of the specific surface area and density of the snow at Dome C and on a transect to Dumont D'Urville, Antarctica - albedo calculations and comparison to remote sensing products, The Cryosphere, 5, 631-649, doi:10.5194/tc-5-6312011, 2011.

Gallet, J.-C., Dominé, F., Savarino, J., Dumont, M., and Brun, E.: The growth of sublimation crystals and surface hoar on the Antarctic plateau, The Cryosphere, 8, 1205-1215, doi:10.5194/tc-8-1205-2014, 2014.

Hansen, A. C. and Foslien, W. E.: A macroscale mixture theory analysis of deposition and sublimation rates during heat and mass transfer in dry snow, The Cryosphere, 9, 1857-1878, doi:10.5194/tc-9-1857-2015, 2015.

Hanson, D. R.: The uptake of $\mathrm{HNO}_{3}$ onto ice, NAT, and frozen sulfuric acid, Geophys. Res. Lett., 19, 2063-2066, doi:10.1029/92GL02182, 1992.

Hobbs, P. V.: Ice physics, Clarendon Press, Oxford, UK, 1974.
Honrath, R., Lu, Y., Peterson, M., Dibb, J., Arsenault, M., Cullen, N., and Steffen, K.: Vertical fluxes of $\mathrm{NO}_{x}, \mathrm{HONO}$, and $\mathrm{HNO}_{3}$ above the snowpack at Summit, Greenland, Atmos. Environ., 36, 2629-2640, doi:10.1016/S1352-2310(02)00132-2, 2002.

Honrath, R. E., Peterson, M. C., Guo, S., Dibb, J. E., Shepson, P. B., and Campbell, B.: Evidence of $\mathrm{NO}_{x}$ production within or upon ice particles in the Greenland snowpack, Geophys. Res. Lett., 26, 695-698, doi:10.1029/1999GL900077, 1999.

Honrath, R. E., Guo, S., Peterson, M. C., Dziobak, M. P., Dibb, J. E., and Arsenault, M. A.: Photochemical production of gas phase $\mathrm{NO}_{x}$ from ice crystal $\mathrm{NO}_{3}^{-}$, J. Geophys. Res., 105, $24183-$ 24190, doi:10.1029/2000JD900361, 2000a.

Honrath, R. E., Peterson, M. C., Dziobak, M. P., Dibb, J. E., Arsenault, M. A., and Green, S. A.: Release of $\mathrm{NO}_{x}$ from sunlightirradiated midlatitude snow, Geophys. Res. Lett., 27, 2237-2240, doi:10.1029/1999GL011286, 2000b.

Hudson, P. K., Shilling, J. E., Tolbert, M. A., and Toon, O. B.: Uptake of nitric acid on ice at tropospheric temperatures: implications for cirrus clouds, J. Phys. Chem. A, 106, 9874-9882, doi:10.1021/jp020508j, 2002.

Huthwelker, T., Ammann, M., and Peter, T.: The uptake of acidic gases on ice, Chem. Rev., 106, 1375-1444, doi:10.1021/cr020506v, 2006.

Hutterli, M. A., Röthlisberger, R., and Bales, R. C.: Atmosphere-to-snow-to-firn transfer studies of $\mathrm{HCHO}$ at Summit, Greenland, Geophys. Res. Lett., 26, 1691-1694, doi:10.1029/1999GL900327, 1999.

Hutterli, M. A., Bales, R. C., McConnell, J. R., and Stewart, R. W.: HCHO in Antarctic snow: preservation in ice cores and air-snow exchange, Geophys. Res. Lett., 29, 1235, doi:10.1029/2001GL014256, 2002.

Hutterli, M. A., McConnell, J. R., Bales, R. C., and Stewart, R. W.: Sensitivity of hydrogen peroxide $\left(\mathrm{H}_{2} \mathrm{O}_{2}\right)$ and formaldehyde (HCHO) preservation in snow to changing environmental conditions: implications for ice core records, J. Geophys. Res., 108, 4023, doi:10.1029/2002JD002528, 2003.

Hynes, R. G., Fernandez, M. A., and Cox, R. A.: Uptake of $\mathrm{HNO}_{3}$ on water-ice and coadsorption of $\mathrm{HNO}_{3}$ and $\mathrm{HCl}$ in the temperature range 210-235 K, J. Geophys. Res., 107, 4797, doi:10.1029/2001JD001557, 2002.

Jacob, P. and Klockow, D.: Measurements of hydrogen peroxide in Antarctic ambient air, snow and firn cores, Fresen. J. Anal. Chem., 346, 429-434, doi:10.1007/BF00325856, 1993.

Jacobi, H.-W. and Hilker, B.: A mechanism for the photochemical transformation of nitrate in snow, J. Photoch. Photobio. A, 185, 371-382, doi:10.1016/j.jphotochem.2006.06.039, 2007.

Jones, A. E., Weller, R., Wolff, E. W., and Jacobi, H. W.: Speciation and rate of photochemical $\mathrm{NO}$ and $\mathrm{NO}_{2}$ production in Antarctic snow, Geophys. Res. Lett., 27, 345-348, doi:10.1029/1999GL010885, 2000.

Jones, A. E., Wolff, E. W., Salmon, R. A., Bauguitte, S. J.-B., Roscoe, H. K., Anderson, P. S., Ames, D., Clemitshaw, K. C., Fleming, Z. L., Bloss, W. J., Heard, D. E., Lee, J. D., Read, K. A., Hamer, P., Shallcross, D. E., Jackson, A. V., Walker, S. L., Lewis, A. C., Mills, G. P., Plane, J. M. C., Saiz-Lopez, A., Sturges, W. T., and Worton, D. R.: Chemistry of the Antarctic Boundary Layer and the Interface with Snow: an overview of the CHABLIS campaign, Atmos. Chem. Phys., 8, 3789-3803, doi:10.5194/acp-8-3789-2008, 2008. 
Jones, A. E., Wolff, E. W., Ames, D., Bauguitte, S. J.-B., Clemitshaw, K. C., Fleming, Z., Mills, G. P., Saiz-Lopez, A., Salmon, R. A., Sturges, W. T., and Worton, D. R.: The multi-seasonal $\mathrm{NO}_{y}$ budget in coastal Antarctica and its link with surface snow and ice core nitrate: results from the CHABLIS campaign, Atmos. Chem. Phys., 11, 9271-9285, doi:10.5194/acp-11-92712011, 2011.

Jones, A. E., Brough, N., Anderson, P. S., and Wolff, E. W.: $\mathrm{HO}_{2} \mathrm{NO}_{2}$ and $\mathrm{HNO}_{3}$ in the coastal Antarctic winter night: a "labin-the-field" experiment, Atmos. Chem. Phys., 14, 11843-11851, doi:10.5194/acp-14-11843-2014, 2014.

Kaempfer, T. and Plapp, M.: Phase-field modeling of dry snow metamorphism, Phys. Rev. E, 79, 031502, doi:10.1103/PhysRevE.79.031502, 2009.

Kärcher, B. and Basko, M. M.: Trapping of trace gases in growing ice crystals, J. Geophys. Res.-Atmos., 109, D22204, doi:10.1029/2004JD005254, 2004.

Kärcher, B., Abbatt, J. P. D., Cox, R. A., Popp, P. J., and Voigt, C.: Trapping of trace gases by growing ice surfaces including surface-saturated adsorption, J. Geophys. Res., 114, D13306, doi:10.1029/2009JD011857, 2009.

Křepelová, A., Newberg, J., Huthwelker, T., Bluhm, H., and Ammann, M.: The nature of nitrate at the ice surface studied by XPS and NEXAFS, Phys. Chem. Chem. Phys., 12, 8870-8880, doi:10.1039/c0cp00359j, 2010.

Kuipers Munneke, P., van den Broeke, M. R., Reijmer, C. H., Helsen, M. M., Boot, W., Schneebeli, M., and Steffen, K.: The role of radiation penetration in the energy budget of the snowpack at Summit, Greenland, The Cryosphere, 3, 155-165, doi:10.5194/tc-3-155-2009, 2009.

Laird, S. K. and Sommerfeld, R. A.: Nitric acid adsorption on ice: a preliminary study, Geophys. Res. Lett., 22, 921-923, doi:10.1029/95GL00817, 1995.

Legrand, M. and Mayewski, P.: Glaciochemistry of polar ice cores: a review, Rev. Geophys., 35, 219-243, doi:10.1029/96RG03527, 1997.

Leu, M.-T.: Laboratory studies of sticking coefficients and heterogeneous reactions important in the Antarctic stratosphere, Geophys. Res. Let., 15, 17-20, doi:10.1029/GL015i001p00017, 1988.

Leu, M.-T., Keyser, L. F., and Timonen, R. S.: Morphology and surface areas of thin ice films, J. Phys. Chem. B, 101, 6259-6262, doi:10.1021/jp963251w, 1997.

Liao, W. and Tan, D.: 1-D Air-snowpack modeling of atmospheric nitrous acid at South Pole during ANTCI 2003, Atmos. Chem. Phys., 8, 7087-7099, doi:10.5194/acp-8-7087-2008, 2008.

Libois, Q., Picard, G., Dumont, M., Arnaud, L., Sergent, C., Pougatch, E., Sudul, M., and Vial, D.: Experimental determination of the absorption enhancement parameter of snow, $\mathrm{J}$. Glaciol., 60, 714-724, doi:10.3189/2014JoG14J015, 2014.

Libois, Q., Picard, G., Arnaud, L., Dumont, M., Lafaysse, M., Morin, S., and Lefebvre, E.: Summertime evolution of snow specific surface area close to the surface on the Antarctic Plateau, The Cryosphere, 9, 2383-2398, doi:10.5194/tc-9-2383-2015, 2015.

Marbouty, D.: An experimental study of temperature-gradient metamorphism, J. Glaciol., 26, 303-312, 1980.
Marchand, P., Marcotte, G., and Ayotte, P.: Spectroscopic study of $\mathrm{HNO}_{3}$ dissociation on ice, J. Phys. Chem. A, 116, 12112-12122, doi:10.1021/jp309533f, 2012.

Marcotte, G., Ayotte, P., Bendounan, A., Sirotti, F., Laffon, C., and Parent, P.: Dissociative adsorption of nitric acid at the surface of amorphous solid water revealed by X-ray absorption spectroscopy, J. Phys. Chem. Lett., 4, 2643-2648, doi:10.1021/jz401310j, 2013.

Marcotte, G., Marchand, P., Pronovost, S., Ayotte, P., Laffon, C., and Parent, P.: Surface-enhanced nitrate photolysis on ice, J. Phys. Chem. A, 119, 1996-2005, doi:10.1021/jp511173w, 2015.

McConnell, J. R., Bales, R. C., Winterle, J. R., Kuhns, H., and Stearns, C. R.: A lumped parameter model for the atmosphere-tosnow transfer function for hydrogen peroxide, J. Geophys. Res., 102, 26809-26818, doi:10.1029/96JC02194, 1997a.

McConnell, J. R., Winterle, J. R., Bales, R. C., Thompson, A. M., and Stewart, R. W.: Physically based inversion of surface snow concentrations of $\mathrm{H}_{2} \mathrm{O}_{2}$ to atmospheric concentrations at South Pole, Geophys. Res. Lett., 24, 441-444, doi:10.1029/97GL00183, 1997b.

McConnell, J. R., Bales, R. C., Stewart, R. W., Thompson, A. M., Albert, M. R., and Ramos, R.: Physically based modeling of atmosphere-to-snow-to-firn transfer of $\mathrm{H}_{2} \mathrm{O}_{2}$ at South Pole, J. Geophys. Res., 103, 10561-10570, doi:10.1029/98JD00460, 1998.

Meusinger, C., Berhanu, T. A., Erbland, J., Savarino, J., and Johnson, M. S.: Laboratory study of nitrate photolysis in Antarctic snow. I. Observed quantum yield, domain of photolysis, and secondary chemistry, J. Chem. Phys., 140, 244305, doi:10.1063/1.4882898, 2014.

Miller, D. and Adams, E.: A microstructural dry-snow metamorphism model for kinetic crystal growth, J. Glaciol., 55, 10031011, doi:10.3189/002214309790794832, 2009.

Murray, K. A., Kramer, L. J., Doskey, P. V., Ganzeveld, L., Seok, B., Van Dam, B., and Helmig, D.: Dynamics of ozone and nitrogen oxides at Summit, Greenland. II. Simulating snowpack chemistry during a spring high ozone event with a 1-D process-scale model, Atmos. Environ., 117, 110-123, doi:10.1016/j.atmosenv.2015.07.004, 2015.

Perrier, S., Sassin, P., and Dominé, F.: Diffusion and solubility of HCHO in ice: preliminary results, Can. J. Phys., 81, 319-324, doi:10.1139/p03-033, 2003.

Picard, G., Brucker, L., Fily, M., Gallée, H., and Krinner, G.: Modeling time series of microwave brightness temperature in Antarctica, J. Glaciol., 55, 537-551, doi:10.3189/002214309788816678, 2009.

Picard, G., Dominé, F., Krinner, G., Arnaud, L., and Lefebvre, E.: Inhibition of the positive snow-albedo feedback by precipitation in interior Antarctica, Nature Climate Change, 2, 795-798, doi:10.1038/nclimate1590, 2012.

Picard, G., Libois, Q., Arnaud, L., Verin, G., and Dumont, M.: Development and calibration of an automatic spectral albedometer to estimate near-surface snow SSA time series, The Cryosphere, 10, 1297-1316, doi:10.5194/tc-10-1297-2016, 2016.

Pinzer, B. R. and Schneebeli, M.: Snow metamorphism under alternating temperature gradients: morphology and recrystallization in surface snow, Geophys. Res. Lett., 36, L23503, doi:10.1029/2009GL039618, 2009. 
Pinzer, B. R., Schneebeli, M., and Kaempfer, T. U.: Vapor flux and recrystallization during dry snow metamorphism under a steady temperature gradient as observed by time-lapse microtomography, The Cryosphere, 6, 1141-1155, doi:10.5194/tc-61141-2012, 2012.

Preunkert, S., Ancellet, G., Legrand, M., Kukui, A., Kerbrat, M., Sarda-Estève, R., Gros, V., and Jourdain, B.: Oxidant Production over Antarctic Land and its Export (OPALE) project: an overview of the 2010-2011 summer campaign, J. Geophys. Res., 117, D15307, doi:10.1029/2011JD017145, 2012.

Pruppacher, H. R. and Klett, J. D.: Microphysics of clouds and precipitation, 2nd revised and enlarged edn., Kluwer Academic Publishers, Dordrecht/Boston/London, 1997.

Riikonen, S., Parkkinen, P., Halonen, L., and Gerber, R. B.: Ionization of nitric acid on crystalline ice: the role of defects and collective proton movement, J. Phys. Chem. Lett., 4, 1850-1855, doi:10.1021/jz400531q, 2013.

Riikonen, S., Parkkinen, P., Halonen, L., and Gerber, R. B.: Ionization of acids on the quasi-liquid layer of ice, J. Phys. Chem. A, 118, 5029-5037, doi:10.1021/jp505627n, 2014.

Röthlisberger, R., Hutterli, M. A., Wolff, E. W., Mulvaney, R., Fischer, H., Bigler, M., Goto-Azuma, K., Hansson, M. E., Ruth, U., Siggaard-Andersen, M.-L., and Steffensen, J. P.: Nitrate in Greenland and Antarctic ice cores: a detailed description of post-depositional processes, Ann. Glaciol., 35, 209-216, doi:10.3189/172756402781817220, 2002.

Seinfeld, J. H. and Pandis, S. N.: Atmospheric chemistry and physics : from air pollution to climate change, Wiley, New York, USA, 1998.

Sigg, A. and Neftel, A.: Seasonal variations in hydrogen peroxide in polar ice cores, Ann. Glaciol., 10, 157-162, 1988.

Sigg, A., Staffelbach, T., and Neftel, A.: Gas phase measurements of hydrogen peroxide in Greenland and their meaning for the interpretation of $\mathrm{H}_{2} \mathrm{O}_{2}$ records in ice cores, J. Atmos. Chem., 14, 223-232, doi:10.1007/BF00115235, 1992.

Sokolov, O. and Abbatt, J. P. D.: Competitive adsorption of atmospheric trace gases onto ice at $228 \mathrm{~K}: \mathrm{HNO}_{3} / \mathrm{HCl}$, 1Butanol/Acetic acid and 1-Butanol/HCl, Geophys. Res. Lett., 29, 1851, doi:10.1029/2002GL014843, 2002.

Sommerfeld, R. A.: A branch grain theory of temperature gradient metamorphism in snow, J. Geophys. Res., 88, 1484-1494, doi:10.1029/JC088iC02p01484, 1983.

Thibert, E. and Dominé, F.: Thermodynamics and kinetics of the solid solution of $\mathrm{HCl}$ in ice, J. Phys. Chem. B, 101, 3554-3565, doi:10.1021/jp962115o, 1997.

Thibert, E. and Dominé, F.: Thermodynamics and kinetics of the solid solution of $\mathrm{HNO}_{3}$ in ice, J. Phys. Chem. B, 102, 44324439, doi:10.1021/jp980569a, 1998.

Thomas, J. L., Stutz, J., Lefer, B., Huey, L. G., Toyota, K., Dibb, J. E., and von Glasow, R.: Modeling chemistry in and above snow at Summit, Greenland - Part 1: Model description and results, Atmos. Chem. Phys., 11, 4899-4914, doi:10.5194/acp-11-48992011, 2011.
Town, M. S., Waddington, E. D., Walden, V. P., and Warren, S. G.: Temperatures, heating rates and vapour pressures in near-surface snow at the South Pole, J. Glaciol., 54, 487-498, doi:10.3189/002214308785837075, 2008.

Toyota, K., McConnell, J. C., Staebler, R. M., and Dastoor, A. P.: Air-snowpack exchange of bromine, ozone and mercury in the springtime Arctic simulated by the 1-D model PHANTAS - Part 1: In-snow bromine activation and its impact on ozone, Atmos. Chem. Phys., 14, 4101-4133, doi:10.5194/acp-14-41012014, 2014.

Traversi, R., Usoskin, I. G., Solanki, S. K., Becagli, S., Frezzotti, M., Severi, M., Stenni, B., and Udisti, R.: Nitrate in polar ice: a new tracer of solar variability, Sol. Phys., 280, 237-254, doi:10.1007/s11207-012-0060-3, 2012.

Traversi, R., Udisti, R., Frosini, D., Becagli, S., Ciardini, V., Funke, B., Lanconelli, C., Petkov, B., Scarchilli, C., Severi, M., and Vitale, V.: Insights on nitrate sources at Dome C (East Antarctic Plateau) from multi-year aerosol and snow records, Tellus B, 66, 22550, doi:10.3402/tellusb.v66.22550, 2014.

Ullerstam, M. and Abbatt, J. P. D.: Burial of gas-phase $\mathrm{HNO}_{3}$ by growing ice surfaces under tropospheric conditions, Phys. Chem. Chem. Phys., 7, 3596-3600, doi:10.1039/b507797d, 2005.

Ullerstam, M., Thornberry, T., and Abbatt, J. P. D.: Uptake of gasphase nitric acid to ice at low partial pressures: evidence for unsaturated surface coverage, Faraday Discuss., 130, 211-226, doi:10.1039/b417418f, 2005.

Valdez, M. P., Dawson, G. A., and Bales, R. C.: Sulfur dioxide incorporation into ice depositing from the vapor, J. Geophys. Res., 94, 1095-1103, doi:10.1029/JD094iD01p01095, 1989.

Wolff, E. W., Jones, A. E., Bauguitte, S. J.-B., and Salmon, R. A.: The interpretation of spikes and trends in concentration of nitrate in polar ice cores, based on evidence from snow and atmospheric measurements, Atmos. Chem. Phys., 8, 5627-5634, doi:10.5194/acp-8-5627-2008, 2008.

Xueref, I. and Dominé, F.: FTIR spectroscopic studies of the simultaneous condensation of $\mathrm{HCl}$ and $\mathrm{H}_{2} \mathrm{O}$ at $190 \mathrm{~K}-$ Atmospheric applications, Atmos. Chem. Phys., 3, 1779-1789, doi:10.5194/acp-3-1779-2003, 2003.

Zhu, C., Xiang, B., Chu, L. T., and Zhu, L.: $308 \mathrm{~nm}$ photolysis of nitric acid in the gas phase, on aluminum surfaces, and on ice films, J. Phys. Chem. A, 114, 2561-2568, doi:10.1021/jp909867a, 2010.

Zondlo, M. A., Barone, S. B., and Tolbert, M. A.: Uptake of $\mathrm{HNO}_{3}$ on ice under upper tropospheric conditions, Geophys. Res. Lett., 24, 1391-1394, doi:10.1029/97GL01287, 1997. 